\title{
La música de los libros de canto llano de la Catedral de Sevilla
}

\author{
The Music of the Plainchant Books \\ of the Cathedral of Seville
}

\author{
Herminio González Barrionuevo \\ Maestro de Capilla de la Catedral de Sevilla. \\ Institución Colombina. Sevilla. España \\ hergonbar@hotmail.com \\ ID ORCID 0000-0001-8135-7121
}

\begin{abstract}
Resumen: El número de libros corales de la catedral de Sevilla asciende casi a trescientos en total, correspondientes a un período de tiempo que va del siglo XV al XX. Los más antiguos, por ser más decorados e iluminados, han sido estudiados por varios especialistas, pero no ha sucedido esto con su música, a pesar de ser la verdadera razón de su existencia. En el presente artículo centramos nuestra reflexión sobre la revisión del canto llano realizada por Sebastián Vicente Villegas, a petición del cabildo de Sevilla, tras la publicación del decreto de Clemente VIII y la doctrina del humanismo extendida por toda Europa después del Concilio de Trento.
\end{abstract}

Palabras clave: canto llano; catedral de Sevilla; canto gregoriano; cantorales; himnarios.

\begin{abstract}
The number of choral books in the Cathedral of Seville amounts to almost 300 in total, corresponding to a period of time that goes from the 15th to the 20th century. The oldest ones, as they are more decorated and illuminated, have been studied by various specialists, but this has not happened with their music, despite being the true reason for their existence. In this article we focus on the revision of plain chant carried out by Sebastián Vicente Villegas, at the request of the Seville cabildo, after the publication of the decree of ClementVIII and the doctrine of humanism spread throughout Europe after the Council of Trent.
\end{abstract}

Keywords: plainchant; Cathedral of Seville; Gregorian Chant; choirbooks; hymnals.

La catedral de Sevilla cuenta al menos con 280 libros corales que contienen 18.886 piezas musicales escritas en el amplio espacio de tiempo que va de la mitad del siglo XV a mediados del siglo XX. Estos grandes libros de canto llano han sido estudiados por los expertos desde el punto de vista de los artesanos que intervinieron en su 
confección y de las miniaturas que poseen estas fuentes, ${ }^{1}$ pero apenas si han sido examinadas sus melodías y demás temas relacionados con la música de sus composiciones hasta el momento, a excepción del repertorio de los himnos; ${ }^{2}$ y eso que la verdadera razón de ser de los libros corales es precisamente el canto llano. ${ }^{3}$ Este repertorio gregoriano ha sufrido alteraciones y variaciones musicales a lo largo de su dilatada historia, como es natural.

En la presente investigación nos fijaremos en las correcciones sistemáticas llevada a cabo por Sebastián Vicente Villegas, por orden del cabildo de la catedral hispalense a comienzos del siglo XVII, tras el Breve publicado por el papa Clemente VIII que alentaba a seguir los principios y las normas emanadas del humanismo renacentista en el canto litúrgico. En nuestro artículo no hemos podido analizar más que un par de cantorales, debido a la extensión requerida para su publicación, pero con ello hemos abierto uno de los caminos a seguir en el futuro, ampliando su estudio a un número mayor de

1 Sobre los escritorios y autores de los libros de música de la catedral puede verse Ma Carmen Álvarez Márquez, El mundo del libro en la iglesia catedral de Sevilla en el siglo XVI, Sevilla, Diputación Provincial, 1992. Sobre las miniaturas: Rosario Marchena Hidaldo, Las miniaturas de los libros de coro de la catedral de Sevilla: el siglo XVI, Sevilla, Universidad de Sevilla y Fundación Focus-Abengoa, 1998; también Diego Angulo Íñiguez, "Libros corales de la Catedral de Sevilla. Siglos XV y XVI", en AA. VV., La Catedral de Sevilla, Sevilla, Ediciones Guadalquivir, 1984, 513-528; María del Rosario Domínguez Benítez, "Libros corales de la catedral de Sevilla. Siglos XVII, XVIII y XIX", en Idem, 529-538.

2 Cf. Herminio GonZÁLez BARRionueVo, "El canto llano mensural de la catedral de Sevilla dentro del contexto español", en Marco Gozzi - Franceso Luisi, Il Canto Fratto. L'Altro Gregoriano. Atti del convengo internazionale di studi Parma - Arezzo, 3-6 dicembre, 2003, Roma, Torre d'Orfeo Editrice, 2005, 281-319; IDEM, “El himnario de la catedral de Sevilla en canto llano", en Anthologica Annua (2020), en imprenta; IDEM, El himnario polifónico destinado a los santos de la catedral de Sevilla. Estudio musicológico y transcripción. Festival de Música Antigua de Sevilla, Sevilla, Editorial Point de Lunettes, Sevilla 2017 (cantorales L37a, L37b, 44a y 44b).

3 A los cantorales propios de la catedral que ascendían a 140 en tiempos de Villegas, como veremos, se unieron más tarde otros grupos hasta alcanzar casi los trescientos libros actuales de canto llano. Se sumaron a los originales de la catedral un grupo de libros de canto procedentes de la Capilla Real; otro del antiguo Colegio de San Isidoro en el compás de San Miguel, donde vivieron y se instruyeron los seises y los acólitos de la catedral durante siglos; otro de la Colegial del Divino Salvador; otro de la Cartuja de Santa María de las Cuevas; y otros pocos del Monasterio de San Isidoro del Campo, antiguamente sede de los monjes jerónimos y en la actualidad despoblado. 
manuscritos, y profundizando aún más sobre su contenido, sin olvidar tampoco otros temas conexionados con su repertorio musical. ${ }^{4}$

\section{VISIÓN HISTÓRICA Y SOCIOCULTURAL DE CONJUNTO}

La transformación de las melodías es algo connatural que camina con el hombre y su entorno, su cultura, sus ideas estéticas y sociológicas, etc. Tenemos innumerables muestras de ello, tanto en la música de tradición oral como en las fuentes musicales religiosas y profanas que van desde la Edad Media hasta nuestros días.

Adaptaciones y revisiones encontramos ya en las fuentes medievales, como sucede en el Gradual de Saint-Yrieux (s. XI) para matizar y precisar algunas cadencias que el revisor consideró poco claras, según sus principios doctrinales; ${ }^{5}$ igualmente en la serie de manuscritos del área germánica, sobre todo, que elevaron la dominante del modo III del si al do, a causa de su inestabilidad y de su clara tendencia hacia la nota supra-semitonal; en las fuentes del Cister del siglo XII, a causa de la reforma sistemática de los cistercienses, en la que trabajó el abad Guido de Cherlieu; ${ }^{6}$ en una serie de cambios y arreglos, aunque menos violentos, que efectuaron los dominicos, en el siglo XIII, y otras órdenes, etc.

Desde el siglo XIII, e incluso ya anteriormente, fue desapareciendo la tradición melódico-rítmica de los libros del repertorio gregoriano, pues las formas de las grafías neumáticas, tan importantes para el ritmo y la verdadera interpretación, comenzaron a no ser tenidas en

4 Cf. GonzÁlez Barrionuevo, “El canto llano mensural”, 281-319.

5 Cf. Nicholas StUaRT, "Melodic "corrections» in an eleventh-century gradual (Paris, B.N., lat.903)", Journal of the Plainsong and Mediaeval Music Society 2 (1979) 2-10.

6 Entre otras cosas, esta reforma mantuvo una norma según la cual el ámbito de las melodías no debía exceder de la octava, que consideraban el ámbito constitutivo de cada modo, más otras dos notas extremas: una aguda y otra grave; $y$, por tanto, se cortaron y alteraron considerablemente sesenta y tres graduales y otras pocas melodías del repertorio del gradual. Hubo también otros cambios sistemáticos, como el que afectó al amplio melisma de la sílaba final del versículo de los aleluyas, que por considerarlo extravagante se cortó. Lo mismo se hizo con algunas repeticiones de frases melódicas, en un grupo melismático. Finalmente, la idea de que la nota fundamental del modo debiera ser la que diera comienzo y terminara cada pieza, dio como consecuencia algunos cambios en ciertas entonaciones y en los finales de la salmodia del introito, por ejemplo. 
cuenta, ${ }^{7}$ y a partir del siglo XIV, al menos, encontramos ya el truncamiento de algunos melismas en las piezas del repertorio gregoriano y la aparición de ciertas obras, aunque particulares y muy concretas, escritas con algunas figuras de carácter mensural. Debido a estas y otras innovaciones medievales, así como al papel confiado a la polifonía y su estrecha relación con el canto gregoriano, fue asentándose una interpretación lenta en el canto de la Iglesia. ${ }^{8}$

La llegada del Renacimiento resucitó el gusto por la antigüedad clásica, hecho que trajo graves consecuencias para el repertorio monódico de la Iglesia, pues los teóricos y los músicos en general, imbuidos por la doctrina humanista que venía extendiéndose por todo Occidente, alentaron el gusto y la preocupación por la prosodia y la inteligibilidad del texto cantado. Como consecuencia, el metro clásico se impuso en los textos, sobre todo en los poéticos del gregoriano, e incluso se recurrió a las figuras mensurales del canto polifónico (larga, breve y semibreve) para expresar la cantidad o duración de

7 Así, por ejemplo, en el Antiphonale Silense, hoy en la British Library Mss Add. 30850 (ca. 1085) se han suprimido sistemáticamente todos los scándicus quilismáticos y casi todos los sálicus, tal como puede verse en Ismael FERNÁNDEZ DE LA Cuesta, (ed.): Antiphonale Silense. British Library Mss Add. 30850. Introducción, indices y edición, Madrid, Sociedad Española de Musicología, 1985. En concreto, todas las veces que aparece la grafía del sálicus en este manuscrito pueden verse en Herminio GonZÁlez BARRIONUEvo, “La grafía del sálicus en la notación «mozárabe» de tipo vertical", Revista de Musicología 12/2 (1989) 397-410.También se han sustituido siempre ambas grafías por pes y scándicus en el antifonario inglés de la Paléographie Musicale de Solesmes, vol. XII (Antiphonaire Monastique XIII Siècle codex F. 160 de la Bibliothèque de la Cathédrale de Worcester, Tournay, Desclée, 1922. Estos comportamientos pueden verse, por ejemplo, en dos antífonas pertenecientes a las Is Vísperas de Navidad: en "a-it" de la antífona Angelus ad pastores, y en "De-us for-tis" de Paroulus filius (fols. 24v y 25/1, y fol. 24/12 del códice silense, y páginas 31/1 y 31/5 del antifonario inglés, respectivamente). Compárese estos lugares con los de la publicación moderna del Antiphonale Monasticum... a Solesmensibus Monachis Restitutum, Tournai, Desclée, 1934, 241/3 y 4 y 242 , respectivamente.

8 Los documentos de la catedral de Sevilla reiteran la doctrina de que cuanto más importante era la fiesta celebrada más lento debía interpretarse el canto gregoriano. Cf. Herminio GonzÁlez BarRionUtevo, "Liturgia, espacios sonoros e intérpretes en la catedral de Sevilla durante los siglos XVII y XVIII", en Pedro Luengo, (coord.), Espacios sonoros en Sevilla (1600-1936), Granada, Centro de Documentación Musical de la Consejería de Cultura y Patrimonio Histórico, 2020, 37-38, 49, 52, 54-55, 60, 67, 79-80, 81, 84 y 86. 
las sílabas en el discurso cantado. . Esto condujo al deseo de revisión y de la "puesta a punto" de las melodías del repertorio gregoriano y su relación con la palabra latina, cuyas sílabas eran consideradas esencialmente largas y breves, y a su vez condicionó la melodía, la notación y la interpretación misma del canto llano. De modo que los músicos volvieron su mirada a la poesía clásica en lugar de dirigirse a las verdaderas fuentes medievales y a quienes habían compuesto las obras; lugares que muestran, en verdad, un lenguaje y un comportamiento muy distintos a la mantenida por los reformadores, como veremos más adelante.

Este era, en gran medida, el ambiente que se respiraba en el siglo XVI, ${ }^{10}$ cuando se celebró el Concilio de Trento (1545-1563) que no trató de la reforma litúrgica, aunque sí entraba en sus planes, sino que, enfrascado en temas de carácter más doctrinal y dogmático, dejó finalmente la reforma litúrgica en manos del Papa, quien a su vez nombró una comisión para la revisión de los libros litúrgicos. ${ }^{11} \mathrm{La}$

9 Pero lo que ocurrió fue, en verdad, no una vuelta real a las doctrinas del período greco-latino, sino una reinterpretación de aquellas y, en consecuencia, de lo que creían los humanistas que decían los clásicos greco-latinos antiguos sobre el discurso fraseológico, las palabras, sus sílabas y acentos.

10 John Merbecke (ca. 1505 - ca. 1585) editó ya en 1550 el The Booke of Common Praier en el que treinta años antes de Guidetti emplea ya una notación de canto llano mensural. Cf. Hyun-Ah KIм, Humanism and the Reform of Sacred Music in Early Modern England: John Merbecke the Orator and The Booke of Common Praier Noted (1550), Ashgate, Aldershot and Burlington, 2008.

11 La cuestión de la música en Trento y del arte en general ha sido ordinariamente magnificada, pues en realidad de lo que se preocupó fue de la relación música-palabra; esto es, de que el texto fuera claro y perceptible para los fieles. La importancia del Concilio se pone de manifiesto durante la larga y difícil aplicación de sus resoluciones. Los números de los decretos que se refieren a la música son muy pocos. En concreto, la sesión XXIII se refiere a que los seminaristas aprendan música en los seminarios; el capítulo 12 de la sesión XXIV, a que los sínodos provinciales se ocupen de precisar lo que se debe cantar en el Oficio de las catedrales e iglesias mayores; en el número 21 de la sesión XXV que se publique el Misal y el Breviario; y en la sesión XXII, al hablar de la celebración de la Misa, advierte que "la Casa de Dios sea casa de oración y sea vista como tal, que sea expulsado de ella todo lo lascivo, ya sea del órgano o del canto, también lo profano y las vanas conversaciones, y que en las iglesias se haga solo verdadera música"; además, considera a la música como medio eficaz para expresar la alabanza divina y mover el "afecto" devoto del corazón de los fieles. Cf. Jorge Piqué Collado, Teología y Música: una contribución dialéctico-trascendental sobre la sacramentalidad de la percepción estética del misterio: Agustín, Balthasar, 
publicación del Breviario (1568) y del Misal (1570) exigía evidentemente la preparación del Antifonario y del Gradual oficiales. Pero esto requería cierto tiempo, de modo que la Santa Sede consideró oportuno, de momento, ir concediendo permisos particulares hasta que aparecieran las ediciones oficiales de canto llano. De todas las ediciones privadas, las más significativas e importantes son dos: el Directorium chori (1582) de Guidetti, ${ }^{12}$ que bien puede considerarse como el primer fruto del movimiento postridentino a favor de la reforma del canto, y la conocida comúnmente como Edición Medicea del gradual (1614) y del antifonario (1615), publicados varios años después en la editorial fundada por el cardenal Fernando de Médici, que representa, más que ninguna otra publicación, el movimiento reformista en su conjunto. ${ }^{13}$

Gregorio XIII tuvo un papel importante en esta carrera de renovación del canto de la Iglesia. ${ }^{14}$ Él fue el primero de los papas postcon-

Sequeri; Victoria, Schönberg, Messiaen, Roma, Editrice Pontificia Università, 2006, 209-210.

12 Hubo varias ediciones de esta obra, en las que sus figuras musicales fueron modificándose y adquiriendo unos contornos mensurales cada vez más precisos. Giovanni Guidetti (1532-1592) fue cantor de la Capilla Sixtina, capellán de Gregorio XIII y alumno de Palestrina. Aprovechando la oportunidad del momento consiguió permiso para editar el Directorium chori... (1582); una obra cuya importancia y significación reside no solo en la revisión, sino también en el hecho de que fue el primer libro de canto completo post-tridentino, y además sirvió de modelo a otras ediciones de canto de los siglos siguientes. Cf. Robert F. Hayburn, Papal Legislation on Sacred Music, 95 A.D. to 1977 A.D., Collegeville, MN, The Liturgical Press, 1979, 44. Estamos ante la primera obra con música tras el Concilio con un sistema explícito de figuras mensurales, donde las sílabas de las palabras llevan una duración en concordancia con la duración y el tipo particular de acento. Además, aparecen melismas truncados y se simplifican las notas de las sílabas átonas, en beneficio de la acentuada. La edición de 1589 ha sido editada, con un estudio introductorio, por María Julieta Vega García-Ferrer - María Luisa García Valverde - Jesús María Morata Pérez - Antonio López Carmona, El Directorium Chori de Giovanni Guidetti. Junta de Andalucía. Consejería de Educación, Cultura y Deporte. Granada, Centro de Documentación Musical de Andalucía de Granada, 2014 <http://www.centrodedocumentacionmusicaldeandalucia.es/opencms/publicaciones/2014/directorium-chori-giovanni-guidetti.html> (consulta: 16-XII-2020).

13 Cf. Joshua Joel Veltman, Prosody and Rhythm in the Post-Tridentine Reform of Plainchant. Tesis doctoral. The Ohio State University, 2004, 55.

14 De hecho, el cabildo de Sevilla se decide a revisar la música de los cantorales apoyado en las directrices presentadas por Clemente VIII, como veremos. 
ciliares que intentó acometer la preparación de la edición oficial de los libros de canto, y mediante la publicación del Breve pontificio Quoniam animaversandum est (25-X-1577) ${ }^{15}$ encargó la revisión del Gradual, del Antifonario y del Salterio a Palestrina y Anibale Zoilo, aunque nunca llegó a finalizarse. Pasado algún tiempo, el editor Raimondi retomó nuevamente la idea de realizar una nueva edición musical y en ello trabajaron Felice Anerio y Francesco Soriano, terminando en pocos años el Temporale (1614) y el Sanctorale (1615) de la tristemente famosa Edición Medicea, pues reescribió el viejo canto gregoriano siguiendo el gusto y estilo estético del siglo XVII, presentando una versión melódica distorsionada con respecto a las fuentes medievales. ${ }^{16}$

El Concilio de Trento alentó aún más las ideas y las ansias de reforma que venían manteniéndose por entonces entre los músicos de la época, llegando incluso a asumirla oficialmente. ${ }^{17}$ Una vez terminado este, las autoridades eclesiásticas comenzaran a aplicar las normas emanadas de sus escritos, incluidas las relativas al repertorio musical, que indirectamente no eran otras que las humanistas extendidas por todas partes, además de Roma. De manera que, a finales del siglo XVI, era opinión común entre los músicos de la

15 Gregorio XIII estableció las directrices para la edición del Antifonario, Gradual, Salterio y otros libros de canto proponiendo la eliminación de todo aquello que fuere contrario a la dignidad y claridad del canto según el criterio indicado por el Concilio de Trento: se eliminen"todos los barbarismos, oscurantismos, contradicciones y cosas superfluas [...] sea por torpeza o por mala fe de los compositores o copistas de los impresos": Piqué Collado, Teología y Música, 210.

16 Paulo $V$ aceptó la idea y renovó por quince años el privilegio de edición de la Medicea a Giovanni Battista Raimondi (31-V-1608), cuyo documento original puede verse en Franz Xaver HaberL, Palestrina e il Graduale Romanum Officiale dell'Editio Medicaea (1614) Contributo alla Storia della Liturgia dopo il Concilio di Trento, Regensburg Friedrich Pustet, 1894, 36. La última edición medicea del Graduale Romanum fue publicada por Pustet (en 1871) con la aprobación de Pío IX, y nuevamente en los años sucesivos; incluso fue declara por Pío IX la única oficial. Esta puede verse online en http://www.gregorianbooks.com/gregorian/ pdf/JDL/Graduale/1871_Graduale_Pustet.pdf. (consultado: 5-II-2021).

17 Marco Gozzi afirma que el ímpetu hacia una reforma litúrgica puede trazarse al menos desde finales del siglo XIV, si uno tiene en cuenta los numerosos pronunciamientos de varios papas, obispos, sínodos y concilios a partir de esta época. Cf. Marco GozzI, "Le edizioni liturgico-musicali dopo il Concilio", en Danilo CURTI - Marco Gozzi (eds.), Musica e liturgia nella riforma tridentina. Provincia Autonoma di Trento. Trento, Servizio Beni Librari e Archivistici, 1995, 39. Con todo, y a pesar de este deterioro, no se encuentran cambios radicales, de modo generalizado, hasta finales del siglo XVI. 
época sostener que las melodías tradicionales del canto llano debían ser expurgadas de ciertos barbarismos y giros melódicos poco agradables, y sobre todo abreviar la línea melódica en muchos lugares de las composiciones, ${ }^{18}$ así se deduce, por ejemplo, de la doctrina de algunos concilios provinciales, ${ }^{19}$ de los escritos de Fernando de las Infantas a Felipe II y al papa Gregorio XIII (1578), del Directorium chori (1582 ${ }^{20}$ de Giovanni Guidetti, y de otros autores más de esta época. ${ }^{21}$ Una adecuación o transformación llevada a cabo al menos desde el siglo XVI, que continuó practicándose hasta la reforma iniciada por san Pío X (1903), tal como ponen de manifiesto las fuentes y las diferentes publicaciones y tratados de canto llano. Bastará citar aquí, por ejemplo, las renombradas ediciones francesas de Nivers $(1697)^{22}$ y aquella de

18 Cf. Luis Villalba Muñoz, "Palestrina y la edición Medicea”, La Ciudad de Dios 54 (1901) 533.

19 En el siglo XVI hubo varios concilios que ordenaron abreviar el canto llano. Por ejemplo, el celebrado en Reims (1564) manda que se abrevien, tanto como fuere posible, las amplias series de notas como existen en ciertas sílabas del canto llano. Y volvió a hacerlo nuevamente otro concilio celebrado en la misma ciudad (en 1583) y casi con los mismos términos, como advierte Théodore NISARD, Études sur la restauration du chant grégorien au XIXe siècle, Rennes, Imprimerie de J.M. Vatar, 1856, 20 (en nota).

20 Cf. Giovanni Domenico Guidetri, Directorium chori ad usum Sacrosanctae Basilicae Vaticanae et aliarum Cathedralium et Collegiatarum Ecclesiarum, Rome, Robert Granjon, 1582. Esta obra tuvo varias ediciones corregidas y ampliadas. Se trata de una especie de guía práctica y de referencia rápida con las piezas necesarias (antífonas, himnos, tonos salmódicos, etc.) para el oficio y la misa, destinado al hebdomadario y cantor de las basílicas romanas, en formato compacto y fácil de usar, pues la mayor parte de las obras llevan únicamente el íncipit o un solo verso. Una de las últimas ediciones lleva este título: Directorium chori ad usum omnium ecclesiarum in quibus officium divinum juxta ritum S. Romanae ecclesiae cantari solet. Ad novam Breviarii romani editionem exactum et recentioribus ac festis pro aliquibus locis adauctum. Sub auspiciis sanctisimi domini nostri Pii PP. IX. curante Sacr. rituum congregatione. Cum privilegio, Ratisbonæ, Neo Eboraci (New York) \& Cincinnatii. Sumtibus, chartis et typis Friderici Pustet, S. Sedis Apost. et Sacr. Rituum Congregationis Typographi, 1874.

21 La obra clásica sobre las ediciones musicales es la escrita por P. Raphael MoLiTor, Die nach-tridentinische Choral-Reform zu Rom. Ein Beitrag zur Musikgeschichte des XVI. und XVII. Jahrhunderts. II: Die Choral-Reform unter Klemens VIII und PaulV (1902), 2 vols. Leipzig, F. E. C. Leuckart, 1901 und 1902. El primer volumen trata de la reforma de Gregorio XIII, y el segundo de Clemente VIII y PauloV.

22 Graduale romanum juxta Missale sacro-sancti concilii Tridentini et S. Pii quinti pontificis maximi authoritate editum. Cujus antiquus Ecclesiae cantus gregorianus e puro fonte Romano elicitus accurate notatur... editado por Guillaume-Gabriel Nivers, 
Reims y Cambrai (París, 1851) dos siglos más tarde. ${ }^{23}$ Todas estas obras de los siglos XVI-XIX, destacaron, entre otras cosas, por el truncamiento y abreviación de los melismas. Insistieron ya en ello varios concilios provinciales del siglo XVI, y a finales del siglo XVII el editor galo Nivers no dudó en considerar el "lujo de vocalizaciones" del canto gregoriano como "un defecto capital". ${ }^{24} \mathrm{El}$ resultado obtenido fue que durante todos estos siglos se abrevió tanto el canto que, como afirma Nisard, en realidad solo llegó a conservase un esqueleto de las antiguas melodías originales, y en muchos casos un tipo de canto llano que no se parecía en nada al verdadero canto gregoriano. ${ }^{25}$

Para hacernos idea de tales comportamientos, tomemos como base el gradual Custodi me: "óculi" (GT 305/4) ${ }^{26}$ que se cantaba el Domingo X después de Pentecostés en el Graduale Romanum, y que la edición de Reims y Cambrai (París, 1851)27 presenta así en la pag. 287, siguiendo, es cierto, al gradual-tonario de Montpellier (s. XI): ${ }^{28}$

París, Christophe Ballard, 1697. Tuvo mucho éxito y fue editado en varios lugares de Francia durante el siglo XVIII. Sus piezas son mucho más cortas, y su canto es mucho más dulce y fluido que el que nos muestra la edición de Reims y Cambrai (1851), reduciendo mucho más las notas de los neumas plurisónicos, debido a que los editores se basaron más en los principios de simplicidad y brevedad que rigieron la reforma realizada en Roma (cf. NISARD, Études sur la restauration, 394395). Estos principios romanos son expuestos por Nisard en las pp. 31-33.

23 Esta edición fue preparada por la comisión nombrada en Cambrai por el arzobispo Giraud (24-XI-1845) para la restauración del canto gregoriano en su archidiócesis. Las ordenanzas del arzobispo pueden verse en Pierre Dupont, "Restauration du chant romain", Reoue de la musique religieuse, populaire et classique 2 (1846) 102-106.

24 Así lo afirma en un folleto impreso por el mismo Guillaume Gabriel Nivers (16321714) titulado: Dissertation sur le chan grégorien, Paris, L'auteur, 1683: < https:// imslp.org/wiki/Dissertation_sur_le_chant_grégorien_(Nivers\%2C_GuillaumeGabriel) $>$ (consulta : 15-XII-2020).

25 Cf. NisARD, Études sur la restauration, 21.

26 GT $=$ Graduale Triplex $\ldots$ Abadía de San Pedro de Solesmes, 1979, que recoge la melodía oficial de la Edición Vaticana del Graduale romanum... (1908). GT coincide con la edición moderna del Graduale Romanum de 1974 en la paginación y el contenido de cada una de estas.

27 Cf. Offices de l'Église du Matin et du Soir suivant le Rit Romain. Entièrement Notés en Plain-Chant d'après le Graduel et l'Antiphonaire, de la Commission de Reims et de Cambrai. Nouvelle Édition sur Cuivre, Paris, Librairie Victor Lecoffre, 1887, 428/7: < https://www.ccwatershed.org/2013/03/19/1887-reims-cambrai-editionrheims/> (consulta: 6-XII-2020).

28 Este manuscrito de la Facultad de Medicina de Montpellier, Ms. H.159 (s. XI), ha sido publicado por los monjes de Solesmes en la Paléographie Musicale, vols. 8 y 9, 


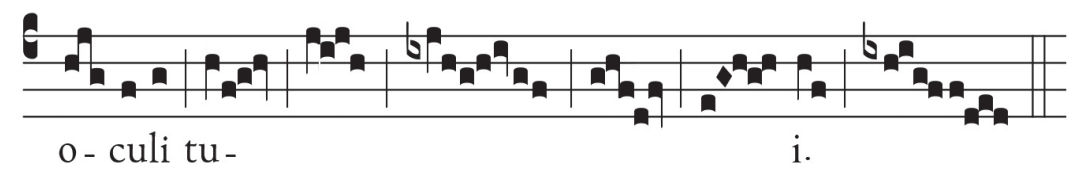

El Graduel romain de Grenoble (1754), de Lyón (1851), de Rennes (1851) y Dijón (1851), abrevian así el pasaje melismático de "tui", dejando solo el comienzo y final del melisma:

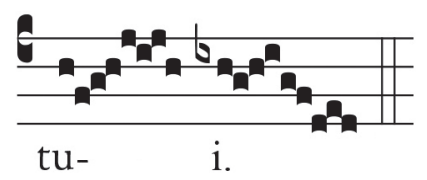

En la edición del Graduale Romanum (Malines, 1848) publicada por Edmond Duval, que sigue a la Edición Medicea de $1614,{ }^{29}$ escribe el pasaje de este modo en la página 82. Una abreviación drástica, como acostumbra a hacer la Edición Medicea, que además no se parece en nada al original, pues resulta ser una pura fantasía. Así se deduce de la comparación ente la versión arriba presentada, que coincide con la Edición Vaticana, y las fuentes antiguas medievales en general, con esta ofrecida por Duval:

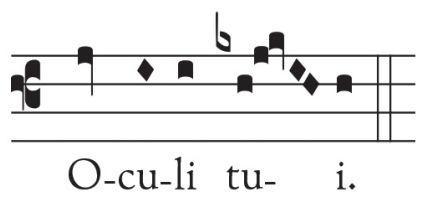

Por lo que se refiere a la acentuación, los reformadores y revisores del canto llano no llegaron a comprender pasajes como el que

Tournai, Desclée, 1901-1905. Si se compara esta melodía con la del GT se advertirán algunas diferencias en la música de ambos libros.

29 Duval fue un musicólogo belga que redescubrió la Edición Medicea en Roma y publicó muchos libros de canto llano a mediados del siglo XIX siguiendo las melodías que él consideraba como las auténticas del verdadero canto gregoriano. Con esta idea fundamental en mente, preparó la reforma litúrgico-musical en Bélgica, apoyado por el cardenal Engelbert Sterckx, arzobispo de Malines. Esta ciudad se convirtió así en uno de los principales centros del canto gregoriano hasta la elección de Pío Xy su verdadera reforma. En “Edmond Duval” de la Wikipedia (edición francesa) puede verse un buen resumen. 
presentamos seguidamente y otros muchos similares. Este pertenece a una de las fórmulas cadenciales "volanderas" más comunes en el repertorio gregoriano, pues la encontramos en todos los modos. Las fuentes de la Edad Media y la Edición Vaticana la escriben de la primera forma, ${ }^{30}$ mientras los reformadores emplean la segunda o bien la tercera, para subrayar el acento y abreviar, sobre todo, la penúltima sílaba de palabra esdrújula. ${ }^{31}$

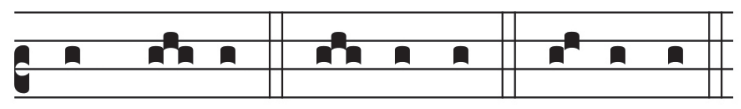

Do- mi- no. Do-mi-no. Do-mi-no.

El estudio del repertorio gregoriano en las fuentes medievales demuestra que los compositores de este repertorio tuvieron siempre presente la importancia de la palabra latina, en la que el acento desempañaba un papel de capital importancia, y por eso lo resaltaron. Pero ellos tuvieron en cuenta un concepto distinto y mucho más amplio con respecto a la belleza melódica y rítmica aplicada al canto gregoriano, pues lo hicieron recurriendo a alguno de los parámetros del sonido: duración, intensidad o altura; basta la presencia de uno de ellos, aunque son frecuentes dos o los tres al mismo tiempo. ${ }^{32}$ Por esta razón, se justifica perfectamente el primer comportamiento presentado arriba, aunque los reformadores modificaron como de costumbre, e hicieron también los cantorales hispalenses que veremos más adelante; esto es, alargando el valor de la sílaba acentuada mediante la adición de notas, y reduciendo el valor, sobre todo, de la penúltima sílaba de "Dómine"33: la sílaba débil de palabra esdrújula.

30 Otro ejemplo, de entre los muchos existentes, puede verse en el Gr. Tecum principium:"princípium" (GT 42/4).

31 Obsérvese cómo se ha escrito la sílaba débil de esdrújula en "Oculi" del ejemplo anterior. Este comportamiento fue constante en este período influido por la doctrina de los humanistas.

32 Cf. Herminio González BarRionuevo, Ritmo e interpretación del canto gregoriano. Estudio musicológico, Madrid, Editorial Alpuerto, 1998. Aunque toda la obra subraya esta realidad, puede consultarse especialmente la segunda y tercera parte.

33 A lo largo de nuestro análisis hemos escrito con frecuencia acento ortográfico (tilde) sobre las palabras, sean del género que sean, para resaltar y facilitar visualmente mejor lo que intenta poner en claro el presente artículo. 


\section{REFORMA DEL CANTO LLANO EN LA CATEDRAL}

La falta de ediciones oficiales de canto en la Iglesia, prácticamente hasta la publicación de la Edición Vaticana del Gradual Romano (1908) y del Antifonario Romano (1912), si exceptuamos los pocos años de la polémica Edición Medicea de $1870,{ }^{34}$ sumió a las catedrales, colegiatas y conventos en general, durante siglos, en un cierto estado de anarquía en relación con el canto llano. Así, frente a la unidad de ceremonias y de plegarias que existía en las celebraciones litúrgicas, después de la publicación de los libros oficiales tras el Concilio de Trento, cada iglesia particular siguió un repertorio de canto llano arreglado a su manera, y en muchos casos incluso con melodías y obras de nueva composición y creación. ${ }^{35}$

Fueron también comunes las revisiones del antiguo repertorio gregoriano recopilado en sus cantorales, para lo cual se apoyaron en un conjunto de doctrinas y leyes comunes en los escritos de la época e incluso visibles ya en fuentes manuscritas y alguna de las ediciones musicales de Europa, sobre todo a partir del Renacimiento, según lo expuesto más arriba. Estos medios impulsaron la adecuación musical de las composiciones al contenido textual, subrayando el papel fundamental de la acentuación verbal, distinguiendo claramente el valor de las sílabas de la palabra, recortando (a veces drásticamente) los melismas, y diseñando la línea melódica de acuerdo con el gusto y el estilo del canto religioso y profano practicado en aquella época; 36 a causa de ello, ambos componentes (texto y música) se vieron

34 Tras los intentos fallidos de Gregorio XIII, Clemente VIII y Paulo V, a través de la Congregación de Ritos, por conseguir la unidad no solo litúrgica, sino también musical, volvió a intentarlo Pío IX en 1868. Para ello nombró una comisión con el fin de publicar nuevamente la antigua Edición Medicea de 1614 y 1615, de acuerdo con los requisitos existentes y a petición de la editorial Pustet de Alemania. Esta nueva edición fue declarada incluso oficial por Pío IX y León XIII para toda la Iglesia, creyendo que contenía el verdadero canto de san Gregorio; una postura que se mantuvo de 1870 a 1904, en que Pío X decidió nombrar la comisión que, con Dom Pothier a la cabeza, preparó la Edición Vaticana del gradual de 1908.

35 Resulta interesante leer a NISARD, Études sur la restauration, 222-236 y 369-370 sobre las divergencias y errores que existen en los distintos libros y la falta de unidad textual y musical.

36 Esto llevó a modificar las melodías originales, deshaciendo las series de stróphicus y en general las notas repetidas y los movimientos melódicos en zigzag, a favor de la línea curva y de carácter más cantable, tal como solía hacerse por entonces en la música religiosa y profana de la época. 
afectados, en mayor o menor medida, según los casos y la decisión última del corrector de turno. Es verdad que se conservaron, en el fondo, las melodías tradicionales, pero sobre esta base del repertorio común, las reducciones contundentes, los arreglos y modificaciones de orden melódico y métrico, se aplicaron en cada centro litúrgicocultual importante (catedral, colegiata, monasterio o convento) de manera particular; dependiendo, en último término, de la tradición y de la persona que realizaba el trabajo de adaptación y revisión de los libros corales del canto llano.

La adopción de la reforma litúrgica tridentina, cuyo calendario litúrgico fue de cumplimiento obligatorio para toda la Iglesia, tuvo lugar en la catedral de Sevilla el 7 de enero de 1575, ${ }^{37}$ y llevó consigo la escritura y adaptación de nuevos libros corales. Uno de los encargados de realizar esta tarea fue Diego Dorta, uno de los escritores de libros de polifonía, de canto llano y miniaturistas más importantes a finales del siglo XVI en la catedral de Sevilla. ${ }^{38}$ El proyecto original comprendía la preparación de 21 libros de canto llano del "nuevo rezado" romano, aunque finalmente se redujo a 18. En el trabajo intervino también su hijo Jerónimo Dorta, que lo finalizó en 1582, poco después de la muerte del padre. Por este trabajo, de“escritura y puntuación y letras iluminadas y principios y encuadernación y toda la demás cosa", recibió 708.560 maravedís.

Treinta y un años más tarde, el Cabildo hispalense decidió revisar y poner al día sus cantorales. Esta vez impulsado por la reforma alentada por ClementeVIII, ${ }^{39}$ para lo cual encargó a Sebastián Vicente

37 "Este dicho día, los dichos señores congregados, como dicho es, mandaron se rece en el coro desta Santa Iglesia el nuevo rezado romano, según y como en él se contiene, y no añadiendo ni quitando cosa alguna..." (Actas Capitulares, lib. 32, 7-I-1575, fol. 205).

38 Perteneció a una familia relacionada con el mundo del libro a lo largo de todo el siglo XVI y trabajó para la catedral, dirigiendo el scriptorium catedralicio por espacio de casi cuarenta años, desde 1574 hasta 1581 en que murió. Tal como puede verse en Álvarez Márquez, El mundo del libro en la catedral de Sevilla, $160-163$ y $180-186$.

39 Clemente VIII realizó revisiones de las ediciones del Breviario (1602), del Misal (1604), y publicó el Pontifical (1596). Pero muchas de las revisiones se limitaron a modificar algunas rúbricas, a la adición de las misas de nuevos santos, y a la inclusión de algunos prefacios en el caso del misal. En verdad, cuando se cita a Clemente VIII, como impulsor de la reforma del Gradual y Antifonario, su labor se concreta en poner en marcha la reforma de estos libros, encomendada a Palestrina y Anibale Zoilo, aunque esto no llegó nunca a terminarse, y a la 
Villegas, clérigo de la veintena y maestro de ceremonias, "la corrección y enmienda de todo el canto llano desta mesma Santa Iglesia", como consta en un documento del archivo catedralicio, fechado el 25 de septiembre de 1613. En este año, la catedral de Sevilla contaba con 140 libros de canto llano para la liturgia, aparte de los que poseían algunas capillas privadas del templo destinados al desarrollo de sus funciones particulares. El tiempo que se había calculado para llevar a término esta ingente labor era de tres años, pero Villegas lo redujo simplemente a uno y medio, y el montante económico del trabajo ascendió a 7.000 reales (230.000 maravedís).

El citado documento dice así:

[Título:]“Libros de canto llano 140 que tiene esta Santa Iga enmendados en punto y letra por el Dr. Sebastián Vicente Villegas, Beneficiado de la Veintena (1613)".

“En 25 de septiembre de 1613, los Sres Deán y Cabildo desta Sta Iglesia de Sevilla cometieron la correción y enmienda de todo el canto llano desta mesma $S^{\text {ta }}$ Iglesia al Lic. Sebastián Vicente Villegas, beneficiado de la veintena Della, el cual, con acuerdo de los $\mathrm{S}^{\text {es }}$ diputados que el mesmo Cabildo señaló y juntamente con el parecer del Maestro de Capilla, enmendo y corrigió 140 libros que para sólo el canto llano esta S ${ }^{\text {ta }}$ Iglesia tiene.

Enmendó en ellos la lectura, conformándola con la del misal y breviario romano, últimamente reformado por la Santidad del Papa Clemente 8, haciendo y componiendo muchos responsos y antífonas y introitos de nuevo, y aun oficios enteros que en ellos no avía.

Enmendó, así mesmo, el mal sonido que en los malos acentos se causaba, por estar ligadas con muchos puntos y prolongadas las sílabas breves, habiendo de estar las dichas ligaduras de puntos y producciones sólo en las largas, conforme al canto reformado por la mesma Santidad del propio Clemente 8 en el pontifical, lo cual casi fue innumerable de contar por ser casi en todas las diciones.

Conformó el punto con la letra en el sentido, haciendo que se significase con el sonido de los puntos lo que iba cantando.

Corrigió últimamente todo el canto en todas las disonancias y asperezas que en él avía, reduciéndolo a la mejor suavidad y melodía que pudo.

publicación del Breve pontificio Quoniam animadversandum est que se basa en la normativa del Concilio de Trento y que los artífices de los libros aplicaron y concretaron de manera personal. De todos modos, existió una interpretación bastante generalizada, tal como vemos en las fuentes y ediciones de los libros a partir de entonces, y esta es también la que aplicó Villegas en la revisión de los cantorales de la catedral de Sevilla. 
Gastó en toda esta correción sólo año y medio, aviendo sido antes informado el Cabildo que no se aría en 3 años.

Fue toda la costa a que todo esto llegó sólo siete mil reales de manufactura, según se presentó (cuando otra vez se hizo desta relación al Cabildo) fe del gasto, [...] aviéndosele informado al Cabildo que llegaría a más de dos mil ducados.

...Quedose por corregir todo el Oficio de difuntos en los libros de los aniversarios, en lo que toca al punto, aunque en la letra se corrigió, como todos los demás, y esto por no atreberse hasta que el cabildo lo mandase particularmente por cierto requerimiento que se le hizo.

Acabose con aprobación del mesmo $\mathrm{M}^{\mathrm{o}}$ de Capilla y de todos los músicos insignes desta $S^{\text {ta }}$ Iglesia, según consta por la relación impresa que se presentó ante el Cabildo". ${ }^{40}$

El documento termina indicando que el cabildo hispalense concedió a Villegas dispensa de asistir a coro los días ordinarios, aunque debía personarse los días de fiesta.

Por tanto, si admitimos como seguro lo que el citado documento dice, y en verdad no hay razón alguna para negarlo, la labor realizada por Villegas consistió en lo siguiente: 1) corrección y enmienda del canto llano en los 140 libros corales con los que contaba la catedral, a excepción de aquellos del oficio de difuntos; 2) enmienda de la lectura, en conformidad con la del misal y breviario romanos reformados por Clemente VIII; 3) composición de muchos responsorios, antífonas, introitos, y oficios enteros de los que carecía la catedral hispalense; 4) corrección del efecto nocivo causado por la mala consideración de los acentos: puntos ligados en sílabas breves, cuando en verdad estos neumas desarrollados debían ir solo en las sílabas largas, conforme al canto reformado por Clemente VIII en el pontifical publicado en 1600; un vicio muy extendido en todos los cantorales; 5) acomodación de las figuras o puntos con el significado de la letra, haciendo que lo que se cantaba estuviera de acuerdo con las notas; ${ }^{41}$

40 Archivo Capitular, Sección IX: Fondo Histórico General (F.H.G.), Legajo 147, pieza 6. El título es de la época en que se cosieron los distintos componentes del legajo, y el documento consta solo de un doble folio con dos páginas y media de texto, cuya signatura antigua es esta: Caxon 47, scaño 3, número 32.

41 Esta acomodación entre las figuras neumáticas y la letra "haciendo que se significase con el sonido de los puntos lo que iba cantando", puede referirse a la escritura de las figuras o puntos de carácter mensural (en compás ternario o binario) y de carácter equalista (medido en compás binario), tal como aparece en los libros corales de la Catedral de Sevilla. 
6) y corrección de todas las disonancias y asperezas del canto, reduciéndolo a la mejor suavidad y melodía posible. ${ }^{42}$ Efectivamente, todo esto aparece reflejado en la notación de los libros corales hispalenses, y lo veremos concretamente en los que analizaremos un poco más adelante. Incluso se halla expuesto en varios principios doctrinales pertenecientes a los tratados escritos porVillafranca yVillegas.

\section{TESTIMONIO DE LAS FUENTES MUSICALES}

Comenzamos este apartado sobre las fuentes musicales de la catedral de Sevilla haciendo referencia a dos tratados importantes de canto llano escritos por dos autores notables de la catedral: Luis de Villafranca ${ }^{43}$ y Sebastián Vicente Villegas. ${ }^{44}$ Los dos fueron publicados en la segunda mitad del siglo XVI y en los inicios del XVII, respectivamente, y reflejan, sin duda alguna, cómo se interpretaba el canto llano en la catedral de Sevilla por estas fechas, donde ellos mismos ejercían su labor de cantores profesionales y profesores de gregoriano. En estos escritos, ambos autores conservan las melodías auténticas del canto llano, sin correcciones ni adaptaciones melódicas en los ejemplos que proponen, frente a lo que observamos en los cantorales del archivo musical corregidos por Villegas. Así lo hace Villafranca cuando cita la primera frase melódico-textual del ofertorio Reges Tharsis (fols. 8v-9 = GT 58), el comienzo del introito Gaudeamus (fol. 10 = GT 619) y la palabra"inveniéntem" de la comunión Beatus serous (fol. 12v = GT 491); lo mismo ocurre en la doxología Gloria Patri... correspondiente a los ocho tonos del magníficat, a los de los responsorios prolijos de los Maitines (LH 604-606) ${ }^{45}$ y a

42 Es evidente que aquí se habla una corrección de la línea melódica de las piezas del repertorio gregoriano de acuerdo con el gusto y los principios estéticos de la época y el parecer particular de la persona que realiza la revisión musical; y esto en un conjunto de composiciones medievales de tradición multisecular que había venido a formar parte del patrimonio musical propio de la Iglesia de Occidente.

43 Breve instrución de canto llano..., Sevilla, Sebastián Trujillo, 1565.

44 Suma de todo lo que contiene el Arte de Canto llano: Cõ muchos importantes avisos assí para saber bien cantar como para regir bien el Coro y para componer en canto llano... compuesta por... Sebastián Vicente Villegas..., Sevilla, en casa de Juan de León, 1604.

$45 \mathrm{LH}=$ Liber hymnarius cum Invitatoriis $\mathcal{E}$ Aliquibus Responsoriis, Solesmes, 1983. 
los de los introitos (fols. 27-33 = GT 822-824). ${ }^{46}$ De igual manera hace Villegas en el inicio de nueve introitos que coloca como ejemplos de entonación de cada uno de los ocho modos del octoecos, ${ }^{47}$ en las doxologías que acompañan a los ocho tonos de los versos de los introitos (pp. 18-23 = GT 822-824) y las correspondientes a los versos responsoriales prolijos de Maitines (pp. 23-26 = LH 604606)..$^{48}$ Este comportamiento se debe seguramente a queVillafranca y Villegas escribieron sus métodos de cantilación y de canto llano en general siguiendo los principios tradicionales del canto al menos en la Iglesia de España, y habían sido publicados años antes de que el cabildo hispalense encargara a Villegas las correcciones de sus cantorales (en 1613).

Pasamos ahora al estudio de las fuentes musicales del archivo de la catedral, y en él nos interesan sobre todo dos puntos fundamentales. En primer lugar, determinar en qué pudieron consistir las revisiones, arreglos y correcciones de Sebastián Vicente Villegas, en el primer cuarto del siglo XVII, por encargo del Cabildo de la catedral hispalense en los cantorales de la catedral; para ello, es necesario analizar algunos de los cantorales hispalenses preparados por Villegas mismo y consecuentemente anotados con las correcciones melódicas oportunas. Además, intentaremos descubrir si la revisión de dichos cantorales fue una novedad, o si por el contrario los cambios que muestran los cantorales del siglo XVII revisados porVillegas,

46 Solo el octavo tono correspondiente a la doxología de los introitos comienza fa, la-sol, sol-do (para Glo, ri, a...) en Villegas (fol. 33) y fa-la, sol, sol-do en Villafranca (p. 22), en lugar de sol, la-sol, sol-do... que hace la Edición Vaticana (GR 824), podría considerarse como una modificación teniendo en cuenta el acento.

47 Villegas nos proporciona la entonación de nueve introitos según los ocho modos del octoecos, seguidos del tono de su verso correspondiente aplicado a la doxología Gloria Patri... (pp. 18-23). Para el Tono I: Gaudeamus y Factus est (p. 18 = GT 619 y 281); para el tono II: Salve sancta Parens (p. 19 = GT 403); para el III: Cognovi Domine (p. 19 = GT 525) en "Domine" se advierte modificación; para el IV: Intret oratio mea (p. 20 = GT 363); para el V: Circumdederunt me (p. 21 = GT 117); para elVI: Os iusti (p. 21 = GT 494); para elVII: Puer natus est (p. 22 = GT 47); y para el VIII: In excelso (p. 22 = GT 257).

48 Solo el cuarto tono comienza igual primero en Villafranca (fol. $29 \mathrm{v})$, pero en este caso se trata más bien de una variante melódica. Además, existen en algunos lugares, tanto en Villafranca como en Villegas, algunas notas y giros melódicos que difieren de los actualmente en uso en los libros de Solesmes, pero se trata de variantes melódicas propias de la práctica hispalense, no de modificaciones del tipo al que nos referimos aquí en nuestro artículo. 
respecto de las fuentes antiguas y como aparecen recogidos en la Edición Vaticana, deben considerarse no como algo nuevo, sino como una tradición que se remonta uno o varios siglos hacia atrás; en este caso, Villegas no habría hecho más que seguir los usos y costumbres de la catedral de Sevilla en lo que respecta al canto llano. Para realizar el estudio comparativo nos fijaremos únicamente a las piezas del Gradual, por ser más constantes en la tradición melódica del repertorio a lo largo de los siglos y presentar, en todo caso, menos variantes melódicas que las obras del Antifonario, por ejemplo, que son más dadas a lecciones particulares de carácter regional y local.

\subsection{En los cantorales del siglo XV}

Entre los cantorales de la catedral de Sevilla más antiguos se cuentan quince que contienen el repertorio del Gradual Romano. ${ }^{49}$ Estos grandes libros, calificados en los documentos de la catedral con el nombre de"gigantes" (= G) fueron confeccionados en el siglo XV, considerando para ello fundamentalmente las características de sus miniaturas, ${ }^{50} \mathrm{si}$ bien alguno de ellos puede situarse posiblemente a comienzos del siglo XVI. De entre estos enormes cantorales hemos elegido únicamente al primero de la serie: el G1, que es uno de los más antiguos con el repertorio de la misa. ${ }^{51}$ Este cantoral "gigante" consta de 67 folios y contiene las misas In festo Sanctorum Apostolorum (fols. 1-25); la de la Vigilia de San Juan y su Fiesta (fols. 26-38); la de San Juan Evangelista (fols. 39-53); la de San Pedro (fols. 54-60); y la de San Pablo (fols. 6167). Además, posee algunas letras iluminadas muy llamativas y bellas. ${ }^{52}$

49 Las letras G y L se refieren a libros "gigantes" y "libretos", de acuerdo con la nomenclatura de uso ordinario en los documentos modernos de la catedral hispalense y en el inventario; ambos grupos de libros, el de grandes dimensiones $(=\mathrm{G})$, y el de formato más reducido (=L), llevan numeración independiente.

50 Cf. la nota 1.

51 Así lo aseguran los especialistas en las miniaturas de estos libros de canto de la catedral de Sevilla, que además atribuyen sus miniaturas a un personaje anónimo que denominan "Maestro de las perlas"; una nomenclatura que aplican a este y otros libros, a causa de la cordada de perlas con que adorna las letras miniadas de dichas fuentes (cf. MARCHENA, Las miniaturas, 112-115).

52 Cuenta con varias iluminaciones espléndidas, y fue miniado por el “Maestro de los Cipreses", denominado así debido a la colocación de algunos árboles de este tipo al fondo de sus pinturas. Las caras de los personajes son anchas y a veces mofletudas, los ojos grandes un poco saltones y el cabello largo y suelto, tal como 
Salvo alguna excepción, centramos nuestro análisis solo en las piezas de G1 contenidas también en el Gradual Romano actual (de 1974), tal y como hechos dicho. De este modo, podremos contar con las versiones melódicas de ambos libros y resultará más clara nuestra reflexión. ${ }^{53}$

1. La primera misa de G1 corresponde a la fiesta de los Santos Apóstoles Felipe y Santiago, cuya antífona de introito Clamaverunt ad Domine (fols. 1-3) no se halla en el gradual romano actual, pero sí en la edición anterior a 1974. Sus dos versículos, que cantan en el tono I, llevan la melodía arreglada conforme a las leyes del acento que ya hemos visto más arriba. Si comparamos el verso Exultate iusti in Domino de dicho introito, cuyo paralelo melódico y textual puede verse aplicado a dos introitos distintos en GT (pp. 452/7 y 619/5), observaremos que la cadencia media de G1, correspondiente al primer hemistiquio del verso, fue modificada en "Dómino" ${ }^{54}$ (fol. 2/2) ya que la clivis (la-sol) se encuentra colocada en la sílaba acentuada, mientras que en la sílaba débil de esdrújula aparece una sola nota (un la). En el segundo hemistiquio del versículo, se ha retocado la entonación, aplicando a la primera sílaba de"réctos" cuatro notas (sol, $f a$, sol, la) y solo una a la final (un la), siguiendo así, en ambos casos,

puede verse en el folio 32v. En este y otros cantorales de esta época participó también el llamado "Maestro de las Perlas", por colocar una especie de collar de perlitas en sus iluminaciones, como se observa, por ejemplo, en el folio 26v.

53 Recomiendo encarecidamente al lector que mantenga abierto el Gradual Romano para consultar cada una de las piezas que se citan (páginas y número de pauta). Contando con ello, he introducido en mi estudio muy pocos ejemplos con música, aunque reconozco que ello sería de gran interés. Pero me lo ha impedido la extensión del presente estudio.

54 Las palabras a las que nos referimos en nuestro análisis van siempre entre comillas, hayan sido corregidas o no por Villegas en los cantorales hispalenses, y las sílabas concretas a las que se alude van escritas en cursiva. Además, las palabras o sílabas subrayadas indican que su música fue modificada porVillegas, y que tal corrección se aprecia con cierta claridad en los lugares concretos de los pergaminos. Por el contrario, la música de las palabras o sílabas entre comillas y no subrayadas no parece que fueran modificadas, aunque la melodía sea distinta a la que vemos en los libros oficiales del Gradual Romano (GT), y se ajuste a las normas seguidas porVillegas en las correcciones de dichos cantorales. De todos modos, aunque en tales casos no se perciba raspadura alguna en el pergamino, ni se vean otros indicios de modificación, debemos tener presente que Villegas efectuó siempre las correcciones melódicas de manera muy discreta; tanto que, muchas veces, resulta difícil percibirlas. 
la norma generalizada de la época, según la cual la sílaba acentuada debía considerarse larga y breve la postónica. ${ }^{55}$ Sebastián Vicente Villegas, revisor de las melodías del canto llano de los cantorales hispalenses, modificó también la cadencia pentasilábica ${ }^{56}$ de "collaudátio" (fols. 2/2-3), a causa de la situación de los acentos del texto; concretamente en"-dátio".

En la doxología Gloria Patri (fols. 1v-2v), que sigue al primer verso Exultate... del citado introito, se mantiene la melodía y el texto tradicional de nuestras ediciones modernas de canto gregoriano, excepto en "Gló-ria...", y seguramente debido al acento de la palabra. ${ }^{57}$ De manera que el notador de G1 colocó el pes o podatus en esta sílaba del acento y no en la siguiente, que era lo normal en la Edad Media, en las ediciones modernas (Cf. GT 822) e incluso en el tratado de Villegas, ${ }^{58}$ pero algo inadmisible en la mentalidad humanista del Renacimiento y de la Contrarreforma.

Por lo que respecta a las otras piezas de la misa, el aleluya lleva una melodía en el modo I y es distinta a la que presenta la Edición Vaticana del Gradual; del ofertorio Confitebuntur solo aparece citado su íncipit textual (fol. 4v = GT 441); y en la comunión Tanto tempore (fols. 4v-6 = GT 560), Villegas ha adaptado la melodía a las normas del acento solo en alguna que otra palabra; concretamente en "Tánto" (fols. $4 \mathrm{v} / 4$ y 5/1), donde se ve que ha sido raspada la música anterior, pero no parece que haya sido transformada la melodía en "témpore" (fol. 5/1), ni en "Patrem" (fol. 5v/2), y en el primer"alelúia" de los dos que aparecen al final de la composición (fol. 6/3), aunque incluso en estos lugares sí se adapta a las normas seguidas por Villegas en sus retoques melódicos a lo largo de G1. De todos modos, en estos tres lugares no se ve que existan raspaduras en los pergaminos; tal vez son variantes melódicas hispalenses, escritas originalmente, ya de

55 Los compositores gregorianos tenían claro que el acento verbal era importante y que existían tres medios fundamentales para subrayarlo: el parámetro de la duración, o bien el de la intensidad o el de la altura. Bastaba uno de ellos, aunque con frecuencia recurren al de la altura. Pero los tonos o fórmulas de la salmodia solemne, a la que correspondían las de los introitos se aplicaba al texto de manera automática, para facilitar su interpretación (cf. GONZÁLEZ BARRIONUEVO, Ritmo e interpretación, 306).

56 Sobre la cadencia cursiva o pentasilábica puede verse GONZÁlez BARRIONUEVO, Ritmo e interpretación, 301-306.

57 Su escritura es la misma que presentamos en el Gloria Patri del último ejemplo musical correspondiente al cantoral G22.

58 Cf.VIllegas, Suma de canto llano, 18. 
este modo, cuando se realizó el citado cantoral en el siglo XV. La verdad es que resulta difícil ver con claridad las raspaduras y los cambios de grafías musicales realizadas por Villegas en muchos sitios de G1, a causa de la maestría con la que actuó este en sus modificaciones melódicas y debido también a la notable calidad del pergamino. ${ }^{59}$

2. A la misa de la Invención de la Santa Cruz (3 de mayo) pertenece el introito Nos autem gloriari (fols. 6v-9 = GT 162) del Jueves Santo, en el que se advierte solo una corrección realizada seguramente porVillegas, quien raspó y modificó las entonaciones del versículo "Deus misereatur..." (7v/1) y de la doxología "Gloria Patri..." (8v/1) que seguía a este y se cantaba naturalmente con su misma melodía. ${ }^{60}$

Existen otras modificaciones melódicas en este mismo introito, pero parecen más bien variantes hispalenses del canto llano que realizó el "puntador" de esta pieza, seguramente copiándolas de otro libro anterior, cuando confeccionó G1 en el siglo XV; pero no parece que sean obra deVillegas, puesto que no se observa raspadura alguna en el pergamino, ni correcciones en la notación musical. Tal ocurre en "áutem" (fol. 6v/1), "Jésu" (fol. 6v/4) y"liberáti" (fol. 7v/1), pero no en "glo-riári (fol. 6v/2) ni en"in quo" (fol. 7/1), pues aquí sí se hallan raspaduras y modificaciones de Villegas. Con todo, en uno y otro caso, aparece reflejada con claridad la doctrina de los humanistas respecto de la adaptación de la melodía al texto, teniendo en cuenta los acentos y las sílabas postónicas de las palabras.

A continuación, ofreceré solamente un ejemplo perteneciente al comienzo de dicho introito (GT 162), en el que el fa del primer "ri" (en "gloriá-ri") debe ser $m i$, en conformidad con las fuentes medievales. ${ }^{61}$ Debajo puede verse el pasaje anotado por el cantoral G-1

59 Efectivamente, no debemos olvidar que las correcciones realizadas por Villegas son tan cortitas y están tan bien realizadas que apenas se advierten si no nos fijamos muy bien en estos pasajes.

60 Se trata del tono correspondiente a la salmodia solemne del modo IV que se empleaba en los introitos hasta la revisión y publicación del nuevo Gradual Romano (1974) en que se suprimió; la música puede verse en GT 823.

${ }_{61}$ Así ha sido restaurado en la edición moderna del Graduale novum editio magis critica iuxta Sacrosanctum Concilium 117 seu Graduale Sanctæ romanæ Ecclesiæ Pauli PP. VI cura recognitum, ad exemplar ordinis cantus missæ dispositum, luce codicum antiquiorum restitutum nutu sancti œecumenici Concilii Vaticani II, neumis laudunensibus et sangallensibus ornatum, Tomus I: de Dominicis et Festis y tomo II de Feriis et Sanctis, Regesnsburg, ConBrio Verlagsgesellschaft - Librería Editrice Vaticana, 2011. 
(fol. 6v) del siglo $\mathrm{XV}$, cuya corrección es muy significativa y común entre los revisores-gramáticos de la época, como tendremos ocasión de comprobar a lo largo del presente estudio.
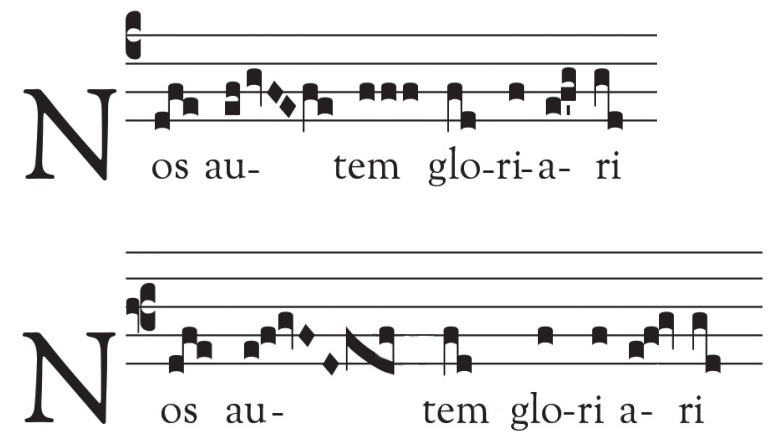

Lo mismo ha sucedido en el aleluya Dulce lignum (fols. 9-11 = GT 598) y en el ofertorio Dextera Domini (fols. 11-12v = GT 194), en el que hallamos muchas variantes melódicas que parecen explicarse por la acomodación de la melodía al texto, siguiendo los principios de la época tantas veces citada, y también por la modificación de la línea melódica a fin de que adquiriera unos contornos más melódicos, según los criterios del momento. Sin embargo, en la comunión Per signum Crucis (fol. 12v-13 = GT 600) podemos decir que solo existe una modificación en relación con las normas humanistas: en "Crúcis" (fol. 12v/2), donde advertimos al final de la palabra una sola nota, suprimiendo las otras tres que muestra el Graduale Romanum actual. Sin embargo, aquí no parece que actuara la mano del corrector (deVillegas), sino que estaríamos ante una variante melódica practicada en Sevilla, pues debió de anotarlo ya de este modo quien"puntó"la música de G1 en el siglo XV.

3. La misa de la Aparición de San Miguel Arcángel (fol. 13-20v) ${ }^{62}$ lleva el introito Benedicite Dominum (fols. 13-15v = GT 607) y en él encontramos pequeños retoques que agilizan un poco más la línea melódica, aunque no debemos olvidar que en este introito del modo III, la Edición Vaticana del gradual ha elevado muchos si al do, como de costumbre. Las modificaciones, para ajustar la melodía a las

62 Esta fiesta se celebraba el 29 de septiembre hasta la renovación del calendario después del Concilio Vaticano II, y se denominaba: Dedicación de la iglesia de San Miguel Arcángel. 
sílabas de ambas palabras, aparecen más claras en "ómnes ángeli" (fol. 13v/1 y 2-3), "vérbum éius" (fol. 13v/4 y 14/1) y "audiéndam vócem" (fol. 14/1-2), donde la sílaba acentuada se elevada melódicamente; así aparece claramente en "ángeli", donde al acento sigue una sola nota (a la $2^{a}$ descendente), colocada en la sílaba débil de esdrújula, y unísono en la sílaba final que lleva un clímacus. Adaptaciones similares ocurren en los dos aleluyas con los que se remata la antífona de este introito (fol. 14/3-4).

En el aleluya Concussum est (fol. 16v-18 = LU 1655) ${ }^{63}$ existen tres variantes melódicas principales a causa de la aplicación de la melodía al texto:"ubi" (fol. 17v/2), "Archángelus Míchael descéndit" (fol. 17v/2, 3 y 4) y "de cáelo" (fols. 17v-18), cuyos acentos vienen subrayados por los parámetros melódico y de duración (elevación melódica y número de notas), frente a las sílabas postónicas que llevan ordinariamente una sola nota en posición más grave. ${ }^{64}$

En el ofertorio Stetit Angelus (fols. 18-19v = GT 610), se ha enfatizado melódica y métricamente el acento de "Ángelus" (fol. 18/2-3), que sigue el comportamiento clásico de esta época también en la manera de tratar las dos sílabas postónicas, aunque añade un melisma luego en la sílaba final. ${ }^{65}$ En "iústa" (fol. 18/3), "áram" (fol. 18/4) y "témpli" (fol. 18/4) se ha subrayado la sílaba acentuada, en mayor o menor medida, llegándose a la final de distinta manera, pero siempre con lógica: mediante una clivis con nota descendente de grado y nota al unísono, respectivamente. En "Thuríbulum" (fol. 18v/2) cantan al unísono las dos últimas sílabas y descenso de $2^{\mathrm{a}}$ respecto del acento; en "áureum" (fol. 18v/2) se han modificado las postónicas, colocando en ellas una sola nota, que se halla al unísono con la precedente; en "éi" (fol. 19/1) se amplía el melisma del acento, y la sílaba final lleva una sola nota al unísono; así termina también "múlta" (fol. 19/2), "arómatum" (fol. 19v/2), y"ascendit" (fol. 19/3-4), donde se muestran

63 Cf. Liber Usualis... París y Tournai, Desclée \& Socii, 1964.

64 Ambas postónicas aparecen al unísono en "Archángeli"; comportamiento que debemos subrayar, puesto que este es un procedimiento generalizado.

65 Este proceder es común. Me refiero a que, una vez realizado el descenso correspondiente, en la final de palabra, puede seguir luego, partiendo de esa nota, un neuma más o menos desarrollado. Tal comportamiento ha sido respetado por los revisores o notadores de los cantorales de la catedral de Sevilla; cosa que no ocurre en otras iglesias, incluso en ediciones impresas del siglo XVI al XX, como puede verse en NISARD, Études sur la restauration. 
modificadas un poco las curvas o vaivenes de la línea melódica del melisma, pero no existe corrección realizada porVillegas, sino que se trata de una variante melódica hispalense, copiada seguramente de otro cantoral anterior, que ya había tenido en cuenta estos principios estéticos de los humanistas que se generalizaron años más tarde.

En la comunión Benedicite omnes angeli (fols. 19v-20v = GT 610) se advierte alguna adaptación, pero aquí los acentos están generalmente bien resaltados, tanto métrica como melódicamente; esto quiere decir que el autor medieval realizó su composición en conformidad con los principios de los revisores de los cantorales hispalenses, por lo cual estos apenas ajustaron algún lugar en esta pieza. De todos modos, nos llama la atención la cadencia final de la obra, sobre la palabra "sáecula" (fol. 20v/2), pues el revisor modificó la antigua ajustándola a las normas humanísticas de la nueva época, ya que colocó en el acento el neuma desarrollado, que se hallaba en la sílaba débil de esdrújula, y escribió una sola nota en las sílabas postónicas: la penúltima al unísono y la última a distancia de $2^{\mathrm{a}}$ descendente, como puede verse a continuación.

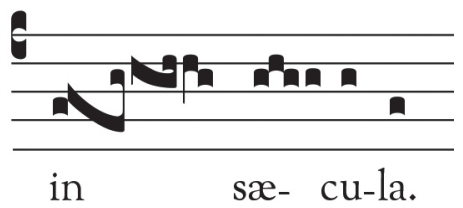

Esta pequeña melodía constituye una fórmula cadencial característica del Déuterus (modos III y IV). Esta parte de una nota más elevada ( $\mathrm{sol}$ ) para descender al $m i{ }^{66}$ y suele hallarse al final de las entidades fraseológicas importantes de dicho modo. Así la encontramos al final de la citada comunión en GT 611:

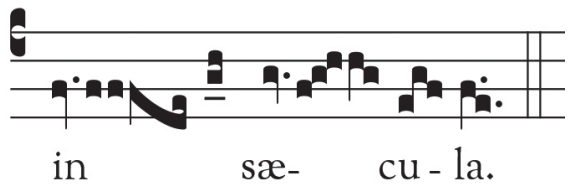

Sin embargo, G-1 (fol. 20v/2) ha transformado esta fórmula cadencial, siguiendo cuidadosamente las normas renacentistas de la

66 Cf. González Barrionuevo, Ritmo e interpretación, 239-240. 
acentuación latina, y ha modificado la relación texto-melodía contra el proceder habitual de las fuentes medievales.

4. La cuarta misa de G-1 está dedicada a los santos Nereo, Arquíleo y Pancracio (fols. 20v-23v), aunque solo lleva introito y comunión y ambas piezas fueron modificadas teniendo en cuenta la relación de la melodía con el texto. En el introito Ecce oculi Domini (fols. 20v-22 y 22v-23 = GT 439), ${ }^{67}$ Villegas, que revisó la obra, amplió el número de notas en el acento de "óculi" (fol. 21/1), dejando en las sílabas postónicas tan solo una nota al unísono y ambas a distancia de $2^{\mathrm{a}}$ descendente; y lo mismo hizo en las sílabas postónicas de "Dómini" (fol. 21/1). Encontramos adaptaciones igualmente en "erípiat" (fol. 21v/1), "a mórte" (fol. 21v/2) y“quóniam" (fol. 21v/4) con la intención de resaltar el acento, tanto en duración como melódicamente, frente a las sílabas postónicas que se comportan de la manera que hemos visto ya repetidas veces. También fueron modificados los dos versículos salmódicos del introito, pertenecientes al tono III; y así el primero muestra una pequeña adaptación en "Dómi-no" (fol. 22v/1) y en "décet collaudátio" (fol. 22v/2), ${ }^{68}$ a fin de que resalten los acentos, como puede verse comparando estos lugares de G-1 con los paralelos de la Edición Vaticana (GT 440/2-3). Lo mismo sucede en el Gloria Patri... correspondiente al mismo tono (fols. 22v-23 = GT 823); concretamente en la sílaba acentuada de "Glória" (fol. 22v/3), resaltada mediante el scándicus sol-la-do, y en las tres primeras de "saeculórum" que llevan estas notas: si-do, do, la-sol-la (fol. 23/3-4). ${ }^{69}$ La mano correctora de Villegas se advierte en "Spirí-tui" (22v/4) de la doxología Gloria Patri..., donde se ven con claridad las raspaduras efectuadas sobre el pergamino para llevar a cabo la modificación de la melodía original escrita en el cantoral.

67 Existe una anomalía en los folios, pues el reverso de este mismo folio (el 22v) lleva el final de una pieza (posiblemente perteneciente al aleluya); sigue luego la comunión Gaudete iusti (fol. 23), en el reverso (fols. 22v más fol. 23 escrito a lápiz), continúan los dos versículos del introito, y en el reverso del folio (el 23v) sigue la comunión.

68 Estas dos palabras parecen variantes hispalenses que ya existían cuando se escribió G1, pues no se advierten correcciones ahora en el pergamino de G1 debidas aVillegas.

69 Luis de Villafranca escribe este tono del Gloria Patri... en su tratado (fols. 28v29) prácticamente igual que GT 823 , a excepción de las dos primeras sílabas de "saecu-lórum", donde anota: si, do-do. 
En la comunión Gaudete iusti in Domino (fol. 23r-v = GT 442), ${ }^{70}$ se observa la presencia de algunas notas nuevas añadidas, si comparamos las melodías del citado cantoral y la que recoge el Gradual Romano. Estas variantes melódicas, entre ambos libros, se ajustan a las normas que ya hemos visto aplicadas a las piezas anteriores; esto es, adición de notas en los acentos y reducción a una sola en la sílaba débil de esdrújula y en la final. ${ }^{71}$ Pero no ha ocurrido esto en la segunda parte de la pieza. Es clásico el tratamiento usado en "Dómino", cuyas dos sílabas finales llevan una sola nota, en posición grave respecto de la última nota del neuma del acento, y con ambas al unísono (fol. 23); sin embargo, no ha sucedido así en "collaudátio" (fol. 23v), donde este pasaje se ha mantenido como el Gradual Romano.

5. La quinta misa es de los santos mártires Gervasio y Protasio y a ella pertenece el introito Loquetur Dominus (fols. 24-26 = GT 369), en el que han sido retocadas, de la forma acostumbrada, las palabras "Dóminus", "súam" (fol. 24) y"convertúntur" (fol. 24v). El verso salmódico del introito, correspondiente al tono III (fols. 25-26), presenta las mismas características que hemos visto ya en el de la misa anterior, también del tono III: "Glo-ria" (25v/1) y"Spi-rítui" (25v/2). ${ }^{72}$

6. La sexta misa corresponde a la Vigilia de san Juan Bautista. En el introito Ne timeas Zacharia (fols. 26v-29v = GT 568), se ha añadido una nota descendente al pes que acompaña a "Ne", convirtiéndose así en tórculus, para que resalte melódicamente el acento de "tímeas" (fol. 26v/1); en "fí-li-um" (fol. 27/2-3) la sílaba acentuada lleva mayor número de notas y las dos últimas solo una (sol, sol), mostrándose aquí ambas finales con descenso de $2^{\mathrm{a}}$ y al unísono; en "má-gnus" (f. 27v/1) ha cambiado el do, doo (o si-doo) que vemos en GT (568/4) por dodo, la para que resalte con claridad el acento; y en "Dó-mino" (27v/2) se ha recurrido a un tratamiento similar, pues frente a la fórmula cadencial, que vemos en los manuscritos medievales, que es la que aparece en el primer ejemplo, los cantorales sevillanos adoptan la segunda, en la que contrasta la duración y la elevación de la sílaba acentuada frente a las postónicas. Así lo anotan GT 568/4 y G-1(fol. 27v/2):

\footnotetext{
Esta pieza continúa tres páginas más adelante en el citado cantoral.

Cf. además la nota 64 .

2 Para las restantes piezas de esta misa, nuestro cantoral hispalense cita únicamente los íncipits textuales.
} 


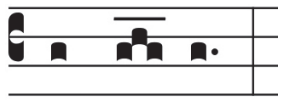

Do-mi- no:

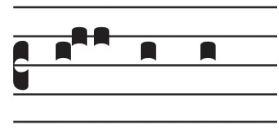

Do- mi-no:

En el gradual Fuit homo (fols. 29v-30v = GT 569) también existen algunas modificaciones. Concretamente, la sílaba acentuada de "hómo" (fol. 29v/2-3) lleva algunas notas más que en los manuscritos antiguos, pues su amplio neuma termina en $f a$, descendiendo luego la sílaba final a re-re-do. Existen también algunas otras transformaciones pequeñas, pero significativas, como ocurre en "cú- $i$ " (fol. 29v/4), en la que Villegas ha anotado $f a-l a$, sol para resaltar el acento. Y hallamos igualmente adaptaciones en el verso responsorial, si bien es verdad que su texto es, a veces, un poco diferente del que ofrece GT 569; de todos modos, se corrigieron las cesuras fraseológicas de mayor o menor importancia, con algunos retoques melódicos en los acentos y algunas sílabas débiles de palabras esdrújulas, tal como ocurre en "testimónium" (fol. 30/4), "lúmine" (fol. 30v/1-2), "Dómino" (fol. 30v/2-3) y"perféctam" (fol. 30v/4).

En el ofertorio Gloria et honore (fols. 30v-31v = GT 434) hallamos una serie de lugares modificados melódicamente por Villagas. Así aparece en "Glória" (fol. 30v/4), al comienzo de la composición, donde el acento lleva un neuma desarrollado, mientras que las dos sílabas postónicas cuentan con una sola nota que desciende, pero ambas al unísono. Intervino también el corrector en "constituísti" (fol. 31/3-4), con el mismo propósito de resaltar el acento y en "ópera mánuum tuárum" (fol. 31v/1, 1-2 y 2), en cuyas tres palabras se establecen otras tantas cesuras fraseológicas del discurso melódico y textual. Junto a estos comportamientos usados por Villegas en sus correcciones melódicas, muy practicados, existe también otro no menos común en "Dómine" (fol. 31v/3), al final del ofertorio, donde tras arreglar un poco la melodía, al final del acento, escribe una sola nota al unísono en las dos sílabas postónicas a distancia de segunda grave (Cf. 31v/2-3). Encontramos también algunos contornos melódicos en "coronás-ti éum" (fol. 31/2), particularmente al final de la primera palabra, que preparan el acento de la segunda palabra, y se ajustan a las normas de los humanistas y a las practicadas porVillegas en su 
revisión de los cantorales hispalenses, pero aquí, en este caso concreto, no se advierten raspaduras en el pergamino ni otros indicios de que Villegas lo corrigiera o modificara.

En la comunión Magna est gloria (fols. 31v-32v = GT 437) existe una acomodación melódica de carácter clásico en "Magna est", pues las dos últimas sílabas figuran al unísono y en descenso de segunda respecto del neuma del acento, pero debemos reconocer que no hay indicios claros de que interviniera aquí la mano de Villegas. En "gloria" se observa un ligero cambio del procedimiento ordinario, pues la sílaba débil de esdrújula cuenta con una sola nota, mientras que la final lleva dos descendentes (= una clivis). Parece cierto que fue Villegas quien modificó la cadencia que tiene lugar en "Dómi-ne" (fol. 32v), haciendo que la sílaba final descendiera de $2^{\mathrm{a}}$ menor ( $\mathrm{fa}$ $\mathrm{mi})$, pero no parece que lo hizo en "gloriam", donde las dos últimas notas descienden de $2^{a}$, manteniéndose ambas al unísono en las dos sílabas finales.

7. La séptima misa de G-1, última analizada aquí, pertenece a la fiesta del día de san Juan Bautista. Su introito De ventre matris meae (fols. 32v-34v = GT 570) presenta modificaciones en "mátris" (fol. 32v/4), donde Villegas resaltó el lugar del acento y escribió en la última sílaba una sola nota al unísono, mientras que en "méae", de la palabra siguiente, no modificó nada, por ajustarse a la norma practicada por los revisores de la época. Este comportamiento que ofrecen ambas palabras en G-1, por ejemplo, demuestra claramente que el adaptador era consciente de lo que debía hacer y dónde debía actuar; otro tanto ocurre en "gládium" (fol. 33/3) y "sagíttam" (fol. 33v/4), donde también ha intervenido la mano del corrector. Es igualmente muy llamativo el arreglo de la entonación "Bónum" (fol. 34/1) y" Gloria" (fol. 34/4) correspondientes al primero y segundo versículos del introito, escritos en el tono $\mathrm{II}^{73}$ en los que se ha resaltado con toda claridad la sílaba acentuada, dejando solo una nota en la final (fol. 34/1); corrección lamentable para nosotros, pero de uso normal entre los tratadistas y la corriente humanista. Esto ha ocurrido en la cadencia final, que de ser pentasilábica, como en "tú-o

73 Tanto Villafranca como Villegas escriben la misma melodía para el tono II de los introitos que vemos en GT 822; solo cambian ambos respecto de GT en la entonación del segundo hemistiquio, donde escriben $r e, f a \ldots$ (cf. Villafranca, Breve instrucción, 28v-29, y Villegas, Suma de canto llano, 19). 
Altísime" que nos muestra el ejemplo primero, tomado del Gradual Romano (GT 570/7), ha pasado a ser hexasilábica, como advertimos en "túo $\underline{\text { Altísime" }}$ "del segundo ejemplo, tomado de G-1 (fol. 34/3-4). ${ }^{74}$

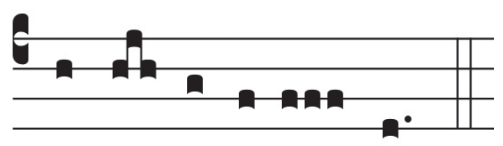

tu- o, Al ti-si- me.

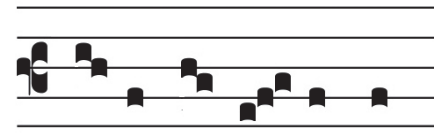

tu- o, Al-ti- si- me.

El tratamiento del versículo Gloria Patri... (fol. 34r-v) es igual que el presentado más arriba, en la misa cuarta del cantoral G-101; ${ }^{75}$ pero con los neumas del"Amen" (fol. 34v/4) distribuidos de manera distinta en uno y otro caso. Seguramente porque allí se ha considerado el "Amén" con acento final, por ser palabra hebrea, y aquí "Á-men" por haberse latinizado.

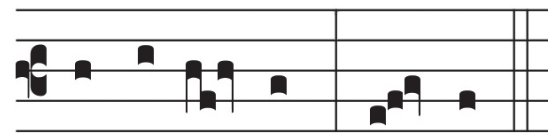

sæ-cu-lo- rum. A-men.

Este tratamiento de revisión es común en el gradual Priusquam te formarem (fols. 35-36 = GT 571), en el que, al iniciarse el verso, en "Mísit" (fol. 35v/3), se ha resaltado melódicamente el acento, añadiéndose una nota inicial; y lo mismo en" míhi" (fol. 36/3-4). En dicho

74 La razón de la no coincidencia entre los acentos textuales de “túo Altísime"y los acentos melódicos, tanto en GT como en las fuentes medievales, puede verse en GONZÁLEZ BARRIONUEVO, Ritmo e interpretación, 306.

75 En el Gradual de la Edición Vaticana (de 1908), el verso doxológico Gloria Patri... de los introitos termina con la misma música del ejemplo precedente:"tuo, Altissime". Estos versos se han suprimido en nueva edición del Gradual Romano de 1974. 
acento, el Gradual Romano actual (1974), siguiendo a las fuentes medievales, lleva solo una nota. El aleluya Tu puer propheta (fols. 35v-36v = GT 571) muestra ciertas modificaciones, respecto de la versión del Gradual Romano, en la cadencia de "Allelú-ia" (re), y en "Tu pú-er", al comenzar el verso, pero no podemos certificar que se deban a Villegas; pueden pertenecer a la época en que se escribió el cantoral G1 o incluso ser anteriores. En el ofertorio Iustus ut palma (fol. 37r-v = GT 497) el corrector, presumiblementeVillegas, ha puesto más de relieve el acento de "Líbano" (fol. 37v/1), y ha escrito solo una nota en la sílaba débil de esdrújula (fol. 37v), haciendo que el neuma desarrollado de la final inicie al unísono con dicha sílaba débil (la penúltima) de la palabra proparoxítona. ${ }^{76}$

En la comunión Tu puer propheta (fols. 37v-38v = GT 572) se observa que Villegas arregló la música de "Tu púer" para que resaltara el acento frente a la sílaba final, que lleva una sola nota al unísono con la precedente. Luego, en "altíssimi" (fol. 38), Villafranca subrayó la sílaba acentuada frente a la débil de esdrújula (penúltima de proparoxítona) que lleva una sola nota escrita a la $4^{\text {a }}$ descendente; la final nos muestra un neuma desarrollado, pero este comienza en unísono con la sílaba anterior. ${ }^{77}$ Finalmente en "vocáberis" (fol. 38), el corrector añadió también algunas notas a la sílaba acentuada, para resaltar esta sílaba ex parte post, ya que las dos postónicas cuentan con una sola nota cada una, al unísono y situadas a distancia de $2^{\mathrm{a}}$ descendente, siguiendo el proceder más generalizado.

\subsection{En los cantorales de Villegas}

Del grupo de los nueve cantorales de la catedral que consta que fueron preparados por SebastiánVicenteVillegas, en el siglo XVII, hemos elegido únicamente dos, teniendo en cuenta su contenido y la presencia de este en los libros de canto modernos; concretamente, tomaremos los cantorales G22 y G101, y compararemos algunas de sus piezas con las versiones melódicas propuestas por el Graduale Romanum (Solesmes, 1974). ${ }^{78}$

76 Este comportamiento de la sílaba final con un neuma desarrollado, pero comenzando al unísono o en posición más grave, respecto de la sílaba anterior, ya lo hemos visto anteriormente y es de uso normal en las revisiones de la época. Cf. la nota 64.

77 Véase la nota precedente.

78 Téngase en cuenta que los cantorales que aparecen con el nombre de Villegas son generalmente antifonarios, y algunos son antifonarios-graduales para fiestas 


\subsubsection{Cantoral G-22}

El cantoral G-22 contiene el Oficio y la Misa de la fiesta de la Corona del Señor. ${ }^{79}$ Para nuestro estudio nos interesa únicamente el introito, ya que las otras piezas de la misa no se hallan en el Gradual Romano actual (de 1974). Así pues, centrando el análisis en el introito Gaudeamus (fols. 60v-64v = GT 545-546), observamos en "Dómino" (fol. 60v/4) y"ángeli" (fols. 61v-62) la adición de notas en el acento, mientras que las sílabas postónicas (débil de esdrújula y final) llevan solo una nota, a distancia de $2^{\mathrm{a}}$ descendente respecto de la última del neuma situado en el acento, y ambas notas cantan al unísono. Lo mismo ocurre en "fílium" (fol. 62/2-3), aunque aquí se ha conservado el melisma original de la última sílaba; pero si prescindimos de este, a partir de la segunda nota, estamos ante el mismo procedimiento de los casos anteriores. Volvemos a observar el mismo comportamiento de las dos sílabas finales al unísono en "Dó-mini" (fol. 61v/1) que también es esdrújula. Como contrapartida, "honó-re" (fol. 61/3-4) y "solemnitá-te" (fol. 61v/3), que son palabras llanas, llevan en la final no un punctum, sino una clivis al unísono con la nota de la sílaba precedente que ha conservado el pequeño neuma original. ${ }^{80}$

Villafranca escribe la segunda palabra del introito Gaudeamus (fol. 10) de la siguiente manera en su tratado Breve instrucción... de

modernas del calendario, o bien recogen misas votivas, celebraciones de Sevilla, e incluso series de piezas más o menos "complementarias" (tales como secuencias, etc.), algo que por otra parte es normal, pues el Temporal y Santoral clásico y tradicional en el calendario de la Iglesia Universal ya existía en los cantorales preparados tras la adopción del "rezado romano" después del Concilio. De hecho, con los libros realizados en el siglo XV y los del XVI habían quedado cubiertas las necesidades de la catedral hispalense (cf. MARCHENA, Las miniaturas, 55-57). Se comprende, pues, que muchas de las obras contenidas en los cantorales analizados en este artículo no existan en el repertorio de cantos de la Edición Vaticana. Además, todo esto concuerda con lo que dice el documento que hemos visto más arriba sobre la misión encomendada por el cabildo de Sevilla a Villegas; esto es, la revisión y acomodación del repertorio a las nuevas ediciones de ClementeVIII.

79 Tras el oficio de $\mathrm{I}^{\mathrm{a}}$ y II ${ }^{\text {as }}$ vísperas (fols. 1-12), maitines (fols. 13v-48), laudes (fols. 44-50), tercia (fols. 53-55), sexta (fol. 56) y nona (fol. 58) aparece la misa (fols. 60v-70), cuyo introito es Gaudeamus del G-22 (fols. 60v-64v).

80 Así lo hace la pieza en "colláu-dant" (f. 62/2), lugar en el que se mantiene el comportamiento original de los antiguos manuscritos medievales. Y de manera similar en la cadencia final, sobre la palabra "De-i" (f. 62/4), aunque aquí la clivis no comienza al unísono, sino a distancia de una $2^{a}$ grave. 
1565; prácticamente como hacen los antiguos manuscritos medievales y la edición vaticana del Gradual Romano (GT 545):

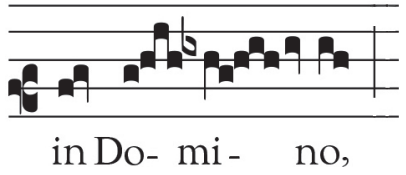

Sin embargo, G-22 (fols. 60v-64v) ha corregido este pasaje y lo ha escrito de la manera que vemos seguidamente.

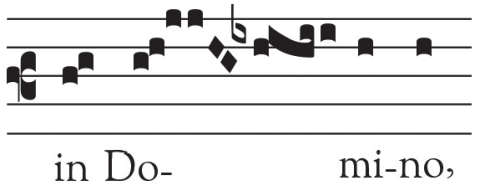

Resulta claro que el notador ha llevado a cabo una transformación de la melodía original, alargando y subrayando la sílaba del acento y reduciendo, al mismo tiempo, el valor de la débil de esdrújula; este es un proceder muy practicado por los revisores del canto llano, tal y como hemos advertido ya anteriormente.

En el verso Omnes gentes (fols. 62v-63), perteneciente al tono I, se unen las tres primeras notas de la entonación (punctum más pes) sobre la primera sílaba ("Óm-nes", fol. 62v/3), por ser esta acentuada, en lugar de seguir el comportamiento de las fuentes medievales; y en la cadencia media de "má-ni-bus" (fol. 63/1) encontramos la clivis en la sílaba acentuada y una sola nota, en posición grave, en la sílaba débil de esdrújula. Sin embargo, en el verso Gloria Patri (fols. 63v-64v) se mantiene el comportamiento de nuestros libros modernos (GT 822), si exceptuamos la entonación de "Gló-ria" (fol. 63v/1) que aparece tratado lo mismo que "Óm-nes".

El ejemplo siguiente nos muestra el comienzo del Gloria Patri, tal como lo recogen Luis de Villafranca (fol. 27) y Sebastián Vicente Villegas (fol. 18), y se ve claramente que la relación entre la melodía y el texto coinciden con la Edición Vaticana (GT 822); lo único que cambia es la presencia de las líneas divisorias que separan cada palabra y las figuras que, mediante el punctum quadratum e inclinatum (=breves y semibreves), sugieren el valor de las notas, tal como dice el mismo autor refiriéndose a los recitativos y a la salmodia. 


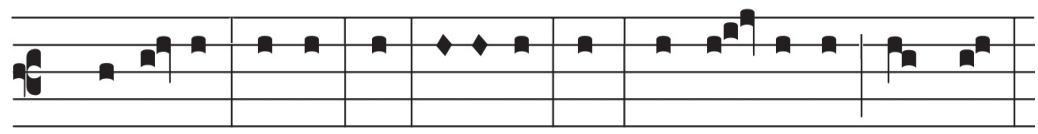

Glo- ri-a Pa-tri et fi-li-o et spi-ri- tu-i san-cto.

Sin embargo, en este otro ejemplo, el cantoral G-22 (fol. 23v) ha corregido la versión antigua de las fuentes, que hemos visto también en Villafranca, y ha colocado las notas de "ri" en la sílaba anterior, donde va el acento, dejando las postónicas solo con una. Pero aquí se usa únicamente notación cuadrada; no las notas romboidales (= punctum inclinatum).

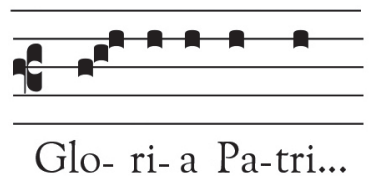

Esto quiere decir que Villafranca y Villegas mantuvieron en sus tratados de canto llano la versión melódica tradicional, mientras que Villegas corrigió años más tarde el comportamiento original y antiguo, en la revisión de los cantores de la catedral hispalense.

\subsubsection{Cantoral G-101}

El cantoral G-101 contiene diez misas votivas de uso común en la catedral de Sevilla: Misa de la Santísima Trinidad (fols. 2v-14v), de los Santos Ángeles (fols. 14v-27v), de Santos Apóstoles Pedro y Pablo (fols. 27v-37), de la Sagrada Eucaristía (fols. 37v-50), del Espíritu Santo (fols. 50v-62v), de la Santa Cruz (fols. 62-74), de la Pasión del Señor (fols. 75-87), por la Reina Madre del Heredero (fols. 89-100), a la Virgen por un parto (fols. 101-112) y a Nuestra Señora de la Paz (fols. 113-122). Nos centraremos solo en las cinco primeras misas, para no alargar demasiado el presente artículo, pues son suficientes para cerciorarnos de las revisiones y correcciones llevadas a cabo por Villegas en los cantorales de la catedral hispalense.

1. La primera misa votiva de dicho cantoral está destinada a la Santísima Trinidad (fols. $2 \mathrm{v}-14 \mathrm{v}$ ), y en ella se emplean las mismas 
piezas que en la de esta fiesta, celebrada el domingo que sigue a la solemnidad de Pentecostés.

En el introito Benedicta sit Sancta Trinitas (fols. 2v-5 = GT 371) hallamos un comportamiento modélico en la aplicación de la melodía al texto, ya que prácticamente todas las palabras siguen las normas de uso general en esta época; de modo que la versión antigua de las fuentes medievales se ajusta a lo que los humanistas opinaban sobre la relación melodía y texto siglos después. En efecto, todas las palabras esdrújulas llevan una sola nota en las dos sílabas postónicas, ambas al unísono, y cantan en posición grave respecto del neuma desarrollado que acompaña a la sílaba del acento; sin embargo, en las palabras llanas, la sílaba postónica suele llevar clivis al unísono o comúnmente a distancia de segunda descendente. Pero el notador ha aplicado la melodía al texto de ambos versículos del citado introito, pertenecientes al tono VIII, buscando una relación estrecha entre las sílabas textuales y la melodía tanto en Dómine Dominus noster como en Gloria Patri (fols. $3 \mathrm{v}-5)$, para lo cual no ha dudado en corregir la versión medieval de las fuentes. ${ }^{81}$

El ejemplo siguiente nos ofrece el comienzo del Gloria Patri según el tono VIII de la salmodia solemne del introito. Así lo escribe Villafranca en su tratado (fol. 33), y una vez más se ve claramente que la relación entre melodía y texto coincide con la Edición Vaticana (GT 824); como en el caso del tono I que hemos visto anteriormente, lo único nuevo es la presencia de las líneas divisorias (en cada palabra) y las figuras, pues con punctum quadratum e inclinatum (=breves y semibreves) sugiere el valor de las notas aisladas, como advierte el autor refiriéndose a los recitativos y a la salmodia, y que Villegas considera como"compás desigual".

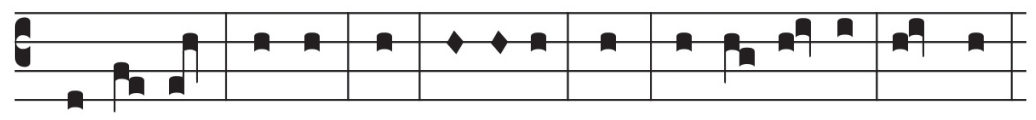

Glo-ri-a pa-tri et fi-li-o et spi-ri-tu-i san-cto.

81 La versión de las fuentes medievales puede verse en GT 371 y 824 para el verso Domine Dominus noster y Gloria Patri, respectivamente. 
El gradual Benedictus es Domine (fols. 4v-6v = GT 372) ha sido revisado todo él siguiendo las normas que hemos visto anteriormente: se ha enfatizado un poco el acento en "Dómine" (fol. 5/5) y más aún en "Chérubim" (fol. 6/1), palabra con la que termina la antífona o caput del gradual:

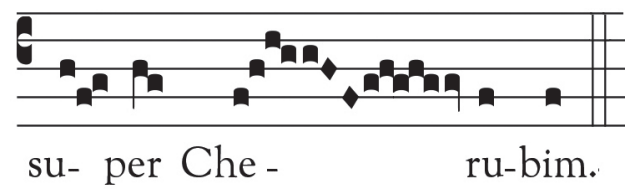

Adviértase el contraste que muestra nuestro cantoral entre la primera sílaba y las dos postónicas, que llevan una sola nota y en unísono, siguiendo así la doctrina clásica de los humanistas; comportamiento que aparece igualmente en "Dómine" (fol. 6/4-5) del verso del gradual. Subrayo aquí, de modo particular, lo ocurrido en "Cherubím", pues resulta de gran interés en el tema que estamos tratando, teniendo en cuenta que las fuentes medievales acentúan la sílaba final por tratarse de palabra hebrea, y ahí es donde va, pues, el melisma; sin embargo, el cantoral G-101 hispalense ha latinizado "Chérubim", pasando el acento de la última sílaba a la primera de dicha palabra, y ha modificado la melodía, de tal modo que no exista ninguna duda de ello. Así lo escribe GT 372/3 siguiendo a las fuentes antiguas:

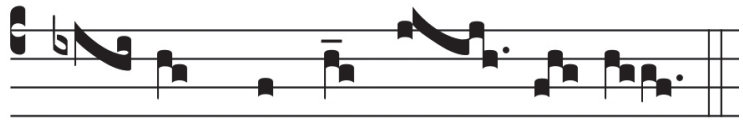

su- per Che-ru-bim.

Otro tanto ha sucedido con el ofertorio Benedictus sit Deus (fols. 11-13 = GT 375) en "Páter" (fol. 11/3-4), cuya última sílaba ha sido despojada de sus notas en beneficio de la acentuada, y se ha quedado solamente con una al unísono. Esta misma reducción drástica se observa en el segundo "ni" de "unigé-ni-tusque" (fol. 11/5), en las dos últimas sílabas de "Fí-lius" (fol. 12v/1), en la última de"Sánctus" (fol. 12v/2), en las dos últimas de "Spí-ritus" (fol. 12v/4), y en la última de "nobís-cum" (fol. 12/1). Ya cerca del final de la antífona ofertorial, en "miseri-córdiam" (fol. 12/2-3), se han añadido varias notas a la sílaba acentuada, reservando dos notas solas al unísono para las 
dos sílabas finales a distancia de $2^{a}$ grave, como de costumbre; y lo mismo ha ocurrido en"súam" (fol. 12/4), cuya sílaba final termina con una sola nota y al unísono.

También se ha modificado la comunión Benedicimus Deum (fols. 13v-14v = GT 376), a fin de resaltar más las sílabas acentuadas y propiciar una disposición más aceptable de la curva melódica a lo largo de la obra. Concretamente, en "Dé-um" (fols. 13v/2-3) y "có-ram óm-nibus" (fol. 13v/4) se han subrayado con mayor claridad las sílabas acentuadas, y a partir de"confitébimur ei" (fol. 14/1-2) se ha modificado la melodía, teniendo en cuenta los acentos y la línea general de la melodía, deshaciendo, en mayor o menor medida, los ascensos y descensos sucesivos, en forma de sierra o vaivén que mostraban las fuentes originales de la época medieval.

2. La segunda misa votiva está dedicada a los Santos Ángeles (fols. $14 \mathrm{v}-27 \mathrm{v}$ ). En el introito Benedicite Dominum omnes angeli (fols. $14 \mathrm{v}-15 \mathrm{v}$ = GT 607) se advierten varias adaptaciones, $\mathrm{y}$ lo mismo en el gradual Laudate Dominum (fols. 17-18v =GT 664). Pero no sucede esto en el ofertorio Stetit ángelus (fols. 24-26 = GT 610) en el que podemos afirmar, en líneas generales, que se mantiene la melodía de las fuentes antiguas sin modificaciones, debido a que en ellas los acentos textuales suelen llevar mayor número de notas, y además suelen situarse en las cumbres que realizan los diseños de las líneas melódicas; condiciones con las que contaban los humanistas, y particularmenteVillegas, a la hora de modificar las melodías del canto llano de nuestros libros corales.

3. La tercera misa votiva es de los Santos Apóstoles Pedro y Pablo (fols. 27v-37) y en ella han sido modificados algunos lugares del introito Mihi autem nimis (fols. 27v-28 = GT 425), del gradual Constitues eos (fols. 30-32 = GT 426) y del aleluya Nimis honorati sunt (fols. 32-33 = GT 431).

4. La cuarta misa votiva es de la Sagrada Eucaristía (fols. 37v-50) y lleva las mismas piezas asignadas por el Gradual Romano actual a la misa del Corpus: el introito Cibavit eos (fols. 37-39v = GT 377) que cuenta con alguna corrección, incluso en el segundo hemistiquio del primer verso (fol. 38v/3-4) que lo anota de esta manera: ${ }^{22}$

82 Compárese con la versión de GT 377/5. 


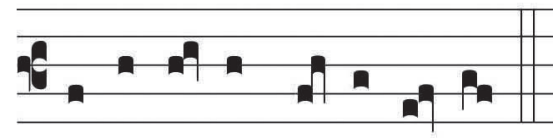

iu-bi-lá- te Dé- o Ja-cób.

También hallamos correcciones a lo largo de todo el segundo verso: la doxología "Gloria Patri" (fols. 38v-39v = GT 822), que está en el tono II y aparece modificado y muy desnaturalizado, debido a la gran preocupación del revisor por resaltar los acentos textuales; así puede comprobarse si comparamos la siguiente versión con la propuesta por GT 822.

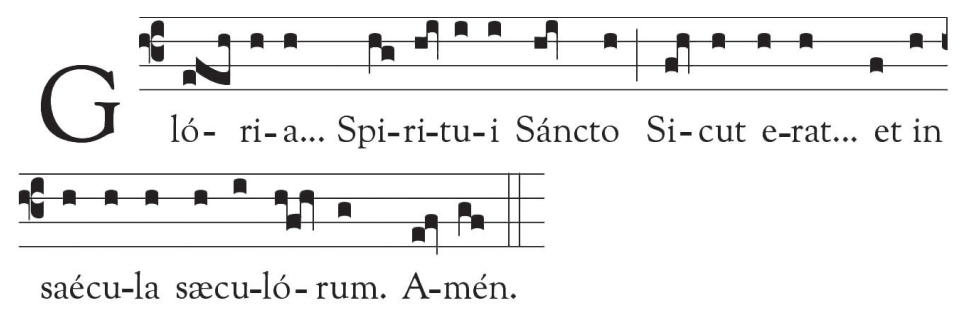

El gradual Oculi ómnium (fols. 39v-41v = GT 343) se muestra notablemente corregido ya al comienzo mismo de la obra. También el aleluya Caro mea (fols. 41v-43v = GT 378) con el fin de poner de relieve los acentos, y lo mismo el ofertorio Sacerdotes Domini (fols. 47-49v = LU 949) ${ }^{83}$ cuyo revisor ha intentado no solo resaltar los acentos, sino precisar también el significado melódico-rítmico de las sílabas débiles de esdrújula y las finales. Sin embargo, la comunión Quotiescumque (fols. 48v-50 = LU 950) mantiene bastante bien su identidad melódica antigua, porque el tratamiento de los acentos se ajustan a las reglas de los humanistas revisores, aunque se advierten correcciones y ajustes en "véniant" (fol. 49/3-4), "córporis" (fol. 49v/5) y“"Dómini" (fol. 50/1-2) donde, además de verse resaltado el acento por el parámetro de la

83 LU = Liber Usualis Miasase et Officii..., París, Tornaci, etc.; Desclée \& Socii, 1964. He citado LU solamente cuando las piezas no se encuentran en Graduale Triplex (1979). La edición oficial del Gradual Romano (de 1908), cuyas piezas aparecen en el LU, fue revisada en el Graduale Romanum de 1974 y el Graduale Triplex (1979); en estas nuevas ediciones se suprimieron algunas piezas del antiguo Gadual Romano (1908), una de las cuales es esta a la que nos referimos aquí. 
altura y duración, sus dos últimas sílabas llevan una sola nota en unísono y a distancia de $2^{\mathrm{a}}$ descendente respecto del neuma plurisónico que acompaña a la sílaba acentuada.

5. La quinta misa votiva está dedicada al Espíritu Santo (fols. 50v-62v), y sus piezas son las mismas de la solemnidad de Pentecostés. Ya al iniciarse el introito Spiritus Domini (fols. 50v-52v = GT 252), el revisor ha corregido las dos primeras palabras "Spíritus Dómini" (fol. 50v/1-2), aplicando la melodía al texto de manera "correcta", según la normativa humanista de la época. Lo mismo hallamos luego en "terrárum" (fol. 50v/4), "cóntinet" (fol. 50v/5), e incluso en“vócis" (fol. 51/3).

El ejemplo siguiente nos ofrece la versión de las fuentes medievales (GT 252) y la del cantoral G-101, fol. 50v (a la derecha) que ha modificado la melodía, colocando mayor número de notas en la sílaba acentuada y, como contrapartida, lo ha reducido al mínimo en las sílabas postónicas por considerarlas breves; el resultado, como puede verse, es ciertamente lamentable.

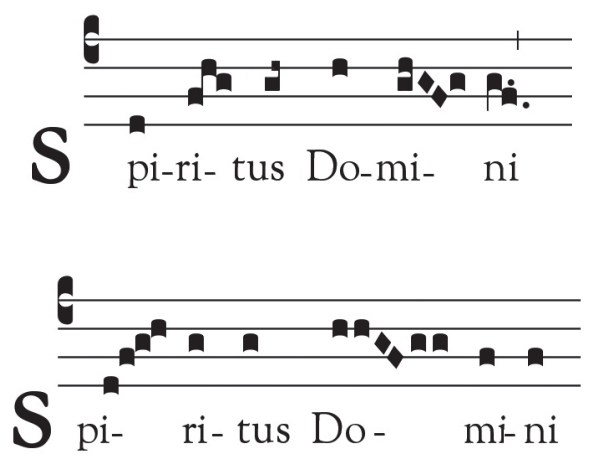

En todos estos lugares, el acento lleva un neuma plurisónico y la melodía se eleva, cayendo en la silaba débil de esdrújula y/o final de la palabra, en la que se halla una sola nota al unísono; sólo en "vócis", con la que se establece la cadencia final de la antífona de introito, la última sílaba lleva una clivis al unísono con la nota precedente; otro de los comportamientos generalizados. ${ }^{84}$ También en la entonación

84 Para ver la melodía original de las fuentes de la Edad Media, recogida además en el Gradual Romano, puede dirigirse el lector a GT 252. Aunque no la he escrito 
del versículo"Exsúrgat" (fol. 51v/1) se ha resaltado el acento, alargando el número de notas y elevando y arreglando la cadencia del tono VIII que debía ser pentasilábica, como hacen las fuentes antiguas.

El gradual Beata gens (fols. 52v-54v = GT 333) comienza con una corrección melódica en la primera palabra, aunque luego conserva la melodía antigua, pues se ajusta generalmente a las normas del acento verbal según la corriente humanista de la época. Por esta misma razón, tampoco el aleluya Veni Sancte Spiritus (fols. 55-56 = GT 253) sufre modificaciones notables, ni el ofertorio Confirma hoc (fols. 60-61 = GT 255), ni la comunión Factus est repente (fols. 61v-62v = GT 2561), a excepción de "Fáctus est" (fol. 61v/1), cuya sílaba acentuada se ha subrayado frente a las otras dos postónicas, siguiendo el principio fundamental adoptado como base de los revisores musicales de la época.

\section{CONCLUSIONES FINALES}

Con el presente artículo espero haber contribuido un poco al conocimiento y estudio de la música en los cantorales de la catedral de Sevilla; un tema que sin duda merece un trabajo mucho más amplio y minucioso que esperamos se realice sin mucha dilación. Del estudio comparativo de las piezas del repertorio del Gradual que hemos visto anteriormente, y del himnario que hemos analizado ya en otro artículo, ${ }^{85}$ se deduce una serie de conclusiones importantes, que trataré de resumir a continuación.

1. Llama la atención que tanto Luis de Villafranca en su Breve instrucción... como Sebastián Vicente Villegas en la Suma de canto llano... hayan conservado las melodías auténticas del canto llano, sin correcciones ni adaptaciones melódicas, en los ejemplos que proponen. ${ }^{86}$ Sin embargo, los cantorales hispalenses corregidos porVillegas sí lo hacen, para resaltar las sílabas acentuadas respecto de las otras, y lo hacen recurriendo para ello al parámetro musical de la altura y al de la duración.

junto a esta del G101 para no alargar el artículo demasiado, pero animo al lector a que compare ambas versiones.

85 Cf. GonzÁlez Barrionuevo, "El himnario de la Catedral de Sevilla".

86 Se comprende que sea así, teniendo en cuenta que ambos autores escribieron sus tratados para enseñar el canto llano tal y como se practicaba tradicionalmente en Sevilla y en España al menos. Ya lo hemos indicado más arriba. 
2. En los cantorales de la catedral de Sevilla, las piezas del Propio de la Misa y las antífonas y responsorios del Antifonario, usan siempre, por lo general, el punctum quadratum como neuma monosónico en solitario sobre una sílaba. En aquellos que constan de dos o más notas, lo normal es que se siga el procedimiento generalizado desde finales del siglo XII y que hallamos actualmente en las ediciones de canto gregoriano; ${ }^{87}$ esto es, en los neumas de dos o más notas ascendentes se escriben puntos cuadrados en escalera, rematándose la serie con una virga final cuando son tres o más, ${ }^{88}$ mientras que en las sucesiones descendentes se anota virga más puntos romboidales, como actualmente en el climacus.

Es evidente que tal notación no supone la existencia de duraciones diversas, como advierte el mismo Villegas cuando afirma que todas las figuras poseen el mismo valor. Sin embargo, este equalismo de las notas en el repertorio general de canto llano se controlaba mediante el compás, conforme afirman tanto Villafranca como Villegas; esto es, aplicando también a los valores iguales un compás binario (mayor o menor), que comúnmente es el denominado "compasillo", tal como afirma Villegas. Por esta razón no se contradicen los teóricos que sostienen que este repertorio es verdaderamente "canto llano" (no mensural), ni quienes afirman, por el contrario, que se mide a compás, porque en verdad lo que se intenta es cantar todas las figuras con duración equivalente, aunque sea batiendo la mano abajo y arriba. Algo que no sucedía en aquellas ediciones de los siglos XVIXIX que, como hemos visto al comienzo de este artículo, usaban también las figuras romboidales como neumas monosónicos y ligaduras fundamentalmente cum opposita proprietate.$^{89}$ Así hacen también, por ejemplo, los cantorales de la reforma hispano-mozárabe de Cisneros.

Las obras de canto llano, tanto manuscritas como impresas, suelen llevar siempre, en España, líneas divisorias para separar cada una

87 No se usa la virga aislada porque esta grafía neumática indica generalmente elevación ex parte ante o ex parte post en los manuscritos medievales, pero en los libros modernos no es necesario este tratamiento, puesto que la notación musical se halla escrita sobre la pauta musical.

88 Esto se hace para facilitar su colocación en la pauta, y así ocurre también con la nota final del porrectus, que se añade a la derecha (hacia fuera) y no hacia dentro, como hace la Edición Vaticana.

89 Aparte de los himnos y de alguna que otra pieza anotada sin duda alguna mensuralmente. 
de las palabras. Esta práctica de separar cada palabra remonta ya a los primeros libros con música del archivo de la catedral hispalense. ${ }^{90}$ Es cierto que Villegas distingue dos tipos de líneas (medias y máximas) y es lógico que así sea, pero habitualmente no suele tenerse en cuenta esta distinción.

3. Los himnos y secuencias forman un repertorio aparte y distinto del resto de piezas gregorianas, pues tanto los himnos como las secuencias solían interpretarse mensuralmente, aunque podemos afirmar que la mayor parte se cantaban con una mensuración binaria, ya sea con figuras diferentes o iguales, en cuyo caso se aplicaba el mismo comportamiento rítmico que hemos visto para las piezas del Gradual. Dado el carácter mensural generalizado en los himnos y secuencias, no debe extrañarnos que lleven notación en los cantorales a base de breves, semibreves, y algunas ligaduras, particularmente las denominadas cum opposita proprietate. ${ }^{91}$ De todos modos, conviene recordar que el repertorio no mensural convivía con el mensural y estas últimas obras pueden medirse en compás tanto binario (compás mayor o menor) como ternario. De esta convivencia y de esta dualidad de compases existe un grupo amplio de casos y así ocurre en los cantorales G19, G28, G92, G99 y G106, por ejemplo, libros que sabemos que fueron realizados por Sebastián Vicente Villegas.

4. Un tercer conjunto de obras lo constituyen los recitativos, de los que hablanVillegas y sobre todoVillafranca; me refiero al formado por las oraciones, epístolas, evangelios, salmodia, lamentaciones, etc. Según estos autores, tales géneros llevan distinta notación, tal como hemos visto, la cual sugiere igualmente una interpretación particular, conocida actualmente como cantilación, y que los teóricos tratan de explicar de la mejor manera posible..$^{92}$ Por eso, según se trate de unos o de otros escritores, se tenderá a un canto semejante a la declamación discursiva, o bien más a la precisión y determinación, en mayor o menor medida, de los valores de cada sílaba del discurso. Lo cierto

\footnotetext{
Cf. GonZÁlez Barrionuevo, El canto llano mensural.

Para los himnos, puede verse GonzÁlez BarRIONuevo, El himnario de la catedral.

La existencia de este triple repertorio de canto litúrgico, con triple tipo de notación en los manuscritos e impresos y consecuentemente su interpretación diferenciada, tal como advierten los tratados, ya fue presentada en GonZÁLeZ BARRIONUEVo, El canto llano mensural, 312-319.
} 
es que en los cantorales de la catedral no contamos con piezas anotadas de este modo, por tratarse fundamentalmente de libros graduales y antifonarios, aunque sí existe salmodia solemne en los introitos, y aquí estas fuentes escriben la notación ordinaria del canto llano; la misma que aparece en la antífona que precede a ambos versículos de los introitos, y como nos muestra Villafranca en su tratado.

5. Los cantorales de la catedral de Sevilla que hemos analizado no abrevian los neumas amplios o melismas, sino que suelen conservarlos, siguiendo así la antigua tradición medieval de las fuentes; únicamente siguen las indicaciones y correcciones propuestas por la corriente humanista que llevó a cabo Villegas. Por tanto, se apartan de la práctica generalizada en las ediciones que hemos visto en la primera parte de este artículo, tanto en el Directorium de Guidetti (1582), en la Edición Medicea (1614 y 1615), y en las ediciones francesas en general.

6. Las composiciones contenidas en los cantorales hispalenses fueron revisadas o arregladas de tal suerte que las palabras adquirieran un tratamiento en conformidad con la mentalidad del humanismo renacentista (y que perduró posteriormente) de considerar largas las sílabas acentuadas y breves, sobre todo, las penúltimas de las proparoxítonas. Pero naturalmente no todas las obras fueron modificadas, ni con la misma profundidad y amplitud. Como consecuencia, en unas piezas y pasajes se muestra, con mayor evidencia, este comportamiento de adaptación de la melodía al texto que en otros lugares; algo fácilmente comprensible, teniendo en cuenta que existen secciones del repertorio gregoriano antiguo que se muestran de acuerdo con las normas propuestas por los revisores y por ello no fueron modificadas.

7. En el estudio de las adaptaciones melódicas que muestran los cantorales de la catedral de Sevilla que hemos visto, se observa siempre, como principio conductor, el deseo de que la sílaba acentuada adquiera mayor preponderancia, tanto desde el punto de vista melódico (posición elevada) como de la duración (número de notas). Esto contrasta con el modo de proceder que presentan ordinariamente las postónicas, en las que suele reducirse, incluso de manera drástica, el número de sus notas, no dudando en colocar una sola nota en la final 
de palabra llana o en las dos últimas de esdrújula; un comportamiento muy generalizado, si bien es verdad que puede partir, de la nota final, un neuma más o menos desarrollado. También es frecuente que las dos sílabas postónicas de las proparoxítonas desciendan de $2^{\mathrm{a}}$ y canten ambas al unísono, mientras que en las palabras paroxítonas la final lleva, muchas veces, una clivis colocada también a distancia de $2^{\mathrm{a}}$ descendente.

8. Además, los cantorales hispalenses han modificado, con frecuencia, la melodía de un determinado pasaje para adecuarla al gusto de la época, que ama la línea melódica en movimiento, sin repetir muchas notas al unísono, ni realizar muchos vaivenes; algo que es frecuente en el repertorio clásico gregoriano. De modo que los revisores del canto llano no dudaron en arreglar la melodía, suprimiendo notas al unísono (bipunctum, tripunctum, etc) y dejando una sola nota, a fin de obtener en el canto un diseño más curvilíneo y en forma de arco romano, si se me permite decirlo así.

9. Las fuentes de canto llano de la catedral de Sevilla aportan testimonios importantes para comprender y precisar en qué pudo consistir la revisión y arreglo realizados por Sebastián VicenteVillegas, en el primer cuarto del siglo XVII, a petición del Cabildo de la catedral hispalense y las indicaciones de Gregorio XIII. En efecto, si nos atenemos a las melodías que recogen dichos cantorales, no podemos por menos que afirmar que hubo una corrección basada en los principios y normas emanadas de los humanistas y la contrarreforma en relación con el texto y la melodía; para quienes el acento era largo y la débil de esdrújula breve. Esto no se puede dudar. 